\title{
Quantifying the thermodynamic entropy budget of the land surface: is this useful?
}

\author{
N. A. Brunsell ${ }^{1}$, S. J. Schymanski ${ }^{2}$, and A. Kleidon ${ }^{2}$ \\ ${ }^{1}$ Department of Geography, University of Kansas, Lawrence, KS, USA \\ ${ }^{2}$ Max-Planck Institute for Biogeochemistry, Jena, Germany \\ Received: 17 January 2011 - Published in Earth Syst. Dynam. Discuss.: 26 January 2011 \\ Revised: 26 April 2011 - Accepted: 15 June 2011 - Published: 20 June 2011
}

\begin{abstract}
As a system is moved away from a state of thermodynamic equilibrium, spatial and temporal heterogeneity is induced. A possible methodology to assess these impacts is to examine the thermodynamic entropy budget and assess the role of entropy production and transfer between the surface and the atmosphere. Here, we adopted this thermodynamic framework to examine the implications of changing vegetation fractional cover on land surface energy exchange processes using the NOAH land surface model and eddy covariance observations. Simulations that varied the relative fraction of vegetation were used to calculate the resultant entropy budget as a function of fraction of vegetation. Results showed that increasing vegetation fraction increases entropy production by the land surface while decreasing the overall entropy budget (the rate of change in entropy at the surface). This is accomplished largely via simultaneous increase in the entropy production associated with the absorption of solar radiation and a decline in the Bowen ratio (ratio of sensible to latent heat flux), which leads to increasing the entropy export associated with the latent heat flux during the daylight hours and dominated by entropy transfer associated with sensible heat and soil heat fluxes during the nighttime hours. Eddy covariance observations also show that the entropy production has a consistent sensitivity to land cover, while the overall entropy budget appears most related to the net radiation at the surface, however with a large variance. This implies that quantifying the thermodynamic entropy budget and entropy production is a useful metric for assessing biosphereatmosphere-hydrosphere system interactions.
\end{abstract}

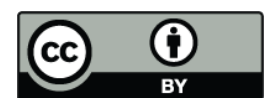

Correspondence to: N. A. Brunsell (brunsell@ku.edu)

\section{Introduction}

A vegetated land surface is inherently far from local thermodynamic equilibrium. As we attempt to understand and ultimately predict how land cover change and regional climate change will impact ecosystem functioning, it may be helpful to understand biospheric processes within the context of thermodynamics. This includes the mostly neglected entropy budget and the second law of thermodynamics (e.g. Schroedinger, 1945; Prigogine et al., 1972).

The Earth's climate system converts low entropy solar radiation into higher entropy terrestrial radiation (Peixoto et al., 1991; Stephens and O'Brien, 1993). The reader is referred to a recent review of the entropy associated with radiative transfer by Wu and Liu (2010). In addition to the entropy production associated with longwave radiation, other sources of entropy production and transfer are surface turbulent fluxes of sensible and latent heat, frictional dissipation, respiration of carbohydrates etc.

In order to better understand the role of the generation and transfer of entropy at the land surface, it is necessary to quantify how the surface converts the incoming solar radiation into the component energy and mass fluxes at short time scales. Using an information theoretic approach, Katul et al. (2001) found a reduction in the Shannon entropy as net radiation signal was transformed into the component energy fluxes by the land surface. They concluded that vegetation "dissipates" the entropy from the received energy forcing variable. However, it is not clear whether the fact that the entropy in each individual transformed signal was lower than the entropy in the net radiation signal indeed implies that the surface dissipated the incoming entropy, as the Shannon entropies of the different fluxes are not additive. The

Published by Copernicus Publications on behalf of the European Geosciences Union. 
thermodynamic entropy may therefore be a more useful measure for the role of vegetation in surface-atmosphere transfer processes, as it is additive and changes in the total entropy of a system are the result of all the entropy exchange and entropy producing processes in the system.

Latent heat transfer fundamentally couples the biosphere and the atmosphere as well as the mass and energy cycles associated with surface-atmosphere transfer processes. Wang et al. (2007) suggested that vegetation attempts to restore local thermodynamic equilibrium by maximizing the transpiration rate. This would imply maximization of the stomatal conductance (Kleidon, 2004) as well as vegetation productivity (Kleidon, 2007). Latent heat transfer is also one of the primary processes associated with entropy production in the atmosphere (Peixoto et al., 1991), which is of particular interest due to its role in acting to remoisten the dehumidification done by atmospheric circulation (Pauluis and Held, 2002a,b).

Using a global circulation model (GCM), Kleidon (2007) found that a 'green' planet has higher entropy production than a "desert" planet. They found that the entropy production due to latent heat transfer was increased in the presence of vegetation, although there was not as much as previously indicated (e.g. Kleidon, 2004). This was due to compensation by altering the relative humidity and in effect continental moisture recycling. A maximization of the latent heat flux would suggest a minimization of the Bowen ratio (ratio of sensible to latent heat flux). This change in the local energy balance partitioning has been shown to have direct impacts on the strength of local surface-precipitation feedbacks (e.g. Brunsell, 2006; Jones and Brunsell, 2009).

Tesar et al. (2007) examined the relationship between plant transpiration and the net entropy production from a forested and a bare soil watershed and found that the vegetated surface contributed higher entropy production due to an increase in transpiration flux as well as a reduction in temperature. Holdaway et al. (2010) extended this by using eddy covariance data over forested and pasture sites in the Amazon and found evidence that ecological succession progresses along a trajectory of maximizing entropy production.

The above results suggest that maximization of entropy production has implications for ecological succession. Schneider and Kay (1994) suggested that ecosystems progress via a maximization of the ability to degrade the incoming solar radiation. Svirezhev (2000) suggested the "entropy pump" hypothesis which states that the entropy production by an ecosystem can be used as a metric for quantifying the anthropogenic stress on an ecosystem. This was extended by Steinborn and Svirezhev (2000) which quantified the entropy production of agricultural sites in Germany. They found that the additional energy input associated with agricultural practices leads to an overproduction of entropy. They showed that the larger the overproduction, the less sustainable the ecosystem.
Patzek (2008) extended this concept and suggested using a thermodynamic metric of the impacts of land cover conversion to assess ecosystem (specifically agricultural) sustainability. By quantifying the change in entropy production due to land cover change, it would essentially be quantifying the distance from thermodynamic equilibrium (Patzek, 2008). Therefore this would be a metric of the work necessary to maintain an ecosystem in such a state. Patzek (2008) used this metric specifically to ascertain the sustainability of agricultural production. Here, we wish to ascertain to what extent the use of the entropy budget and entropy production can be a useful metric of biogeographic variability more generally. This could potentially provide a thermodynamic basis for assessing future land cover transitions and the impacts of ecosystem functioning under altered climate. If nothing else, extending the analysis of ecosystem dynamics to include both the first and second laws of thermodynamics should provide a more complete understanding of the Earth system. First, we must understand the role of vegetation on entropy transport and production.

Therefore, the goal of this research is to quantify the role of vegetation on the entropy budget and entropy production at the land surface. We utilize a land surface model to compute the associated radiant, mass and energy fluxes as a function of the fractional vegetation cover. These fluxes are then used to calculate the entropy budget and relate the changes in entropy production to the vegetation's ability to transfer net radiation into the turbulent fluxes. Eddy covariance observations collected over three different land cover types are then used to calculate the entropy budget from observations of surface-atmosphere exchange.

\section{Methods}

\subsection{Entropy budget at the land surface}

The net radiation at the surface $\left(R_{\mathrm{n}},\left[\mathrm{W} \mathrm{m}^{-2}\right]\right)$, i.e. the net balance between incoming and outgoing radiation streams is partitioned at the land surface between the turbulent transport of sensible $(H)$ and latent heat fluxes ( $\left.\mathrm{LE},\left[\mathrm{W} \mathrm{m}^{-2}\right]\right)$ as well as heat conduction into the ground by the soil heat flux $(G$, [W $\left.\left.\mathrm{m}^{-2}\right]\right)$ :

$R_{\mathrm{n}}=Q_{\mathrm{S}}+Q_{\mathrm{L}, \text { in }}-Q_{\mathrm{L}, \text { out }}=H+\mathrm{LE}+G+\epsilon$

where $Q_{\mathrm{S}}\left[\mathrm{W} \mathrm{m}^{-2}\right]$ is the absorbed solar radiation and the $Q_{\mathrm{L}}\left[\mathrm{Wm}^{-2}\right]$ terms represent the incoming (in) and outgoing (out) long wave $\left(L,\left[\mathrm{~W} \mathrm{~m}^{-2}\right]\right.$ ) radiation streams respectively.

There is also a residual of the energy budget $(\epsilon)$ to account for the energy terms that are not considered in the other fluxes (e.g. photosynthesis). This term also accounts for the instantaneous rate of heating. Note that this term is often neglected by the climate modeling community where one of the energy balance terms is often calculated by residual in order to force 
closure of the energy balance, due to the necessity of conserving energy at the global scale. However, when considering a local energy balance, there can be smaller scale processes which account for some energy (e.g. photosynthesis) that is not accounted for in the other terms. This is significant for our purposes since we will be applying this approach to measurements obtained with eddy covariance, for which energy balance closure is rarely observed (Wilson et al., 2002).

Figure 1 portrays a schematic view of the radiative and heat fluxes associated with the land surface.

Now we wish to consider the entropy budget associated with these fluxes. The entropy terms due to solar radiation $d S_{Q_{S}}$ consists of two components (1) an entropy transfer $\left(J,\left[\mathrm{~J} \mathrm{~K}^{-1} \mathrm{~m}^{-2} \mathrm{~s}^{-1}\right]\right)$ and (2) an entropy production $(\sigma$, $\left.\left[\mathrm{J} \mathrm{K}^{-1} \mathrm{~m}^{-2} \mathrm{~s}^{-1}\right]\right)$ term associated with the absorption and conversion of the low entropy solar radiation to heat. Note that for this application, we are determining these values from the measured or modeled fluxes measured per unit area and thus these are technically entropy transfer per unit area and entropy production per unit area. These are calculated as:

$J_{Q_{\mathrm{S}}}=\frac{Q_{\mathrm{S}}}{T_{\mathrm{sun}}}$

$\sigma_{Q_{\mathrm{S}}}=Q_{\mathrm{S}}\left(\frac{1}{T_{\mathrm{sfc}}}-\frac{1}{T_{\text {sun }}}\right)$

where the temperature of the sun $\left(T_{\text {sun }},[\mathrm{K}]\right)$ is assumed to be constant at $5780 \mathrm{~K}$ and $T_{\mathrm{sfc}}[\mathrm{K}]$ is the radiant surface temperature. Note that this is an approximation disregarding the directional aspect of solar radiation (Wu and Liu, 2010).

The longwave radiation is treated similarly, with the entropy transport due to longwave radiative flux $\left(J_{Q_{\mathrm{L}}}\right.$, $\left.\left[\mathrm{J} \mathrm{K}^{-1} \mathrm{~m}^{-2} \mathrm{~s}^{-1}\right]\right)$ :

$J_{Q_{\mathrm{L}}}=J_{Q_{\mathrm{L}, \text { in }}}-J_{Q_{\mathrm{L}, \text { out }}}=\frac{Q_{\mathrm{L}, \text { in }}}{T_{\mathrm{atm}}}-\frac{Q_{\mathrm{L}, \text { out }}}{T_{\mathrm{sfc}}}$

and the entropy production due to absorption of longwave radiation and conversion to heat $\left(\sigma_{\mathrm{L}},\left[\mathrm{J} \mathrm{K}^{-1} \mathrm{~m}^{-2} \mathrm{~s}^{-1}\right]\right)$ :

$\sigma_{Q_{\mathrm{L}}}=Q_{\mathrm{L}, \text { in }}\left(\frac{1}{T_{\mathrm{sfc}}}-\frac{1}{T_{\mathrm{atm}}}\right)$

where the radiant temperature of the atmosphere $\left(T_{\mathrm{atm}},[\mathrm{K}]\right)$ is calculated by inverting the Stefan-Boltzmann law with the downwelled thermal emission term and assuming an atmospheric emissivity of 0.85 (Campbell and Norman, 1998). Since the longwave radiant emission from the atmosphere is a function of the emission and absorption spectra over the entire atmosphere, the temperature $T_{\mathrm{atm}}[\mathrm{K}]$ is not the same as the near surface air temperature $\left(T_{\mathrm{a}}[\mathrm{K}]\right.$ in Fig. 1).

The entropy transfer associated with the sensible heat flux $\left(J_{H},\left[\mathrm{~J} \mathrm{~K}^{-1} \mathrm{~m}^{-2} \mathrm{~s}^{-1}\right]\right)$ is:

$J_{H}=\frac{-H}{T_{\mathrm{sfc}}}$
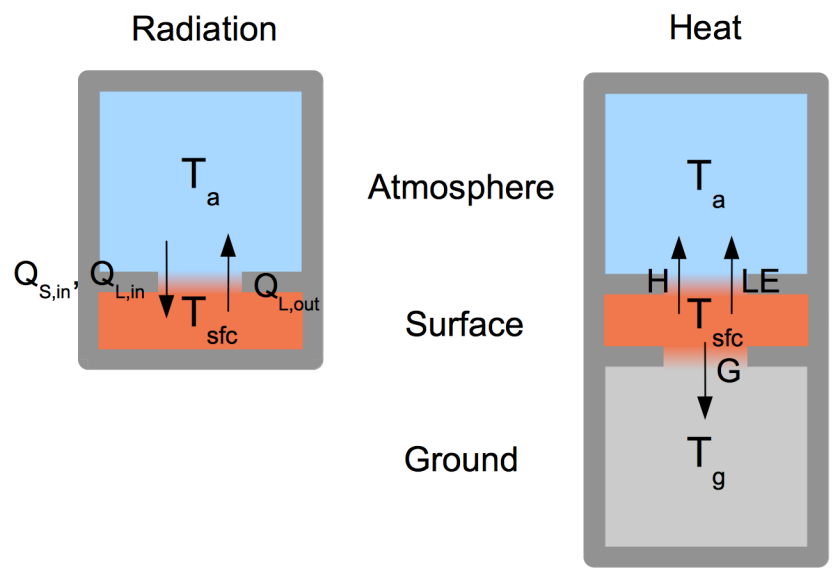

Fig. 1. Schematic view of the (left) radiation and (right) heat fluxes considered in the entropy budget.

The entropy transfer associated with conduction into the soil $\left(J_{G},\left[\mathrm{~J} \mathrm{~K}^{-1} \mathrm{~m}^{-2} \mathrm{~s}^{-1}\right]\right)$ is analogous:

$J_{G}=\frac{-G}{T_{\text {sfc }}}$

The entropy transport associated with the latent heat flux ( $J_{\mathrm{LE}},\left[\mathrm{J} \mathrm{K}^{-1} \mathrm{~m}^{-2} \mathrm{~s}^{-1}\right]$ ) is computed as:

$J_{\mathrm{LE}}=\frac{-\mathrm{LE}}{T_{\mathrm{sfc}}}$

where $T_{\mathrm{sfc}}[\mathrm{K}]$ is the temperature at which the entropy transfer occurs (i.e. the surface).

The total entropy transfer $\left(J,\left[\mathrm{~J} \mathrm{~K}^{-1} \mathrm{~m}^{-2} \mathrm{~s}^{-1}\right]\right)$ for the land surface is then:

$J=J_{Q_{\mathrm{L}}}+J_{Q_{\mathrm{S}}}+J_{H}+J_{\mathrm{LE}}+J_{G}$

The entropy production $\left(\sigma,\left[\mathrm{J} \mathrm{K}^{-1} \mathrm{~m}^{-2} \mathrm{~s}^{-1}\right]\right)$ by the land surface is:

$\sigma=\sigma_{Q_{\mathrm{S}}}+\sigma_{Q_{\mathrm{L}}}$

The overall thermodynamic entropy budget of the land surface is then given by the sum:

$\frac{\mathrm{d} S}{\mathrm{~d} t}=J+\sigma$

Note that in this formulation we are not considering any entropy transport or production associated with precipitation, subsurface transport of water, photosynthesis etc. (Kleidon and Schymanski, 2008).

\subsection{NOAH land surface model simulations}

In our numerical experiment, the individual radiant and surface energy fluxes were computed using the NOAH land surface model, which is a well established, community based model that has been tested and validated in a wide range 
of environments (e.g. Sridhar, 2002; LeMone et al., 2008; Chen and Zhang, 2009). It is also one of the land surface schemes available in several regional climate models including MM5 and WRF, which makes it one of the primary land surface models for assessing local to regional scale impacts of surface heterogeneity and surface-atmosphere exchange processes.

The NOAH land surface model used here is version 2.7.1, which is available from: ftp://ftp.emc.ncep.noaa.gov/mmb/ gcp/ldas/noahlsm/ver_2.7.1/basic. This model has been described in great detail in other publications (e.g. Chen and Dudhia, 2001a,b; Ek et al., 2003), and the reader is referred to those publications for a technical description of the model physics.

For the control runs we utilized the "Basic" version of the model with the forcing meteorology and the input file as it is distributed with the source code. The forcing data used for all model runs is also that which accompanies the model distribution. This data was collected at the Bondville Ameriflux site $\left(40.01^{\circ} \mathrm{N}, 88.37^{\circ} \mathrm{W}\right)$ located in central Illinois, US (e.g. Meyers and Hollinger, 2004) in 1998. The forcing data consisted of half hourly values of seven meteorological variables: air temperature $\left(T_{\mathrm{a}}\right)$ at $3 \mathrm{~m}$, relative humidity, surface pressure, incoming solar radiation, rainfall, average wind vector speed, and incoming longwave radiation.

The model results in outputs of all the energy and the radiative fluxes which were not specified as input. The effective radiant temperature of the atmosphere $\left(T_{\mathrm{atm}}\right)$ and the surface temperature $\left(T_{\mathrm{sfc}}\right)$ are calculated from the output radiation streams by inverting the Stefan-Boltzmann law ( $L=\epsilon \sigma T^{4}$ ) with the appropriate longwave radiant flux.

The primary purpose of the model analysis was to examine the impact of the vegetation fraction $\left(F_{\mathrm{V}}\right)$ on the surface entropy budget and production of entropy at the land surface. Therefore we conducted a series of simulations that altered the surface vegetation fraction to assess the impact of this change. The vegetation fraction $\left(F_{\mathrm{V}}\right)$ was varied in $20 \%$ increments from 0 to $100 \%$ coverage. The surface albedo was scaled between a bare soil value appropriate for a silt-loam $\left(\alpha_{\mathrm{s}}=0.25\right)$ and a full vegetation value $\left(\alpha_{\mathrm{v}}=0.18\right)$ which was chosen to match the maximum value in the NOAH-LSM basic input file. The intermediate albedo values are calculated as a linear fraction of the vegetation cover:

$\alpha=\alpha_{\mathrm{s}}\left(1-F_{\mathrm{V}}\right)+\alpha_{\mathrm{v}} F_{\mathrm{V}}$

Note that in these simulations the same forcing meteorological data was used as in the control run. Therefore there is no feedback between the land surface and the atmospheric fields in this analysis.

\subsection{Eddy covariance observations}

In addition to the theoretical impacts associated with the fractional cover of vegetation we examined the thermodynamic entropy budget associated with observations of landatmosphere exchange. We calculated the thermodynamic entropy budget from observations made using eddy covariance flux towers from three sites in Kansas, US. These sites compose three distinct land cover types within a relatively small geographical area. Each of the sites are fully vegetated during the peak of the growing season. One year data (2008) was used for each of the sites to investigate the nature of the entropy budget.

Two of the sites were located at the Konza Prairie Long Term Ecological Research site near Manhattan, Kansas. These sites were located on watersheds that have an annually burned (site KZU) and a four year burn cycle (K4B). This variation in burn regime has resulted in different vegetative species combinations resulting in the different watersheds. Site KZU is a relatively homogeneous, predominantly C4 grassland with some minor C3 forb species, while K4B is a mixture of $\mathrm{C} 4$ grassland and woody vegetation due to the lack of fire suppressing the woody encroachment.

The third eddy covariance station was located approximately $150 \mathrm{~km}$ east of Konza at the University of Kansas Field Station (KFS), located near Lawrence, Kansas. This site is burned infrequently, approximately every four years. The land cover is more heterogeneous due largely to the historical use at the site. The site was used intensively for agricultural purposes until the 1960s, while in the 1970s and 1980s a cool season grass was planted (Bromus inermis). Burning approximately every five years has maintained the site as a grassland until 2007 when the eddy covariance station was installed. Currently, KFS consists of a mixture of $\mathrm{C} 3$ and and some native $\mathrm{C} 4$ grasses and a small fraction of woody vegetation.

All of the eddy covariance data is collected and processed in the same manner. Windspeed and temperature data is collected using a Campbell Scientific CSAT-3 sonic anemometer and the water flux is collected using a Li-Cor 7500 open path gas analyzer which is inclined into the mean wind at an angle of $15^{\circ}$.

Turbulence measurements are stored at $20 \mathrm{~Hz}$ and are post processed using Edi-Re (version 1.4.3.1167, R. Clement, University of Edinburgh, UK) and R (R Development Core Team, 2010, www.r-project.org). Post processing of the data is conducted as is described in Baum et al. (2008), but follows generally accepted practices including planar-fit corrections (Paw U et al., 2000), and corrections for fluctuations in the air density (Webb et al., 1980). Quality control was conducted using the integral turbulence characteristics and stationarity tests (Foken and Wichura, 1996; Hammerle et al., 2006).

As the sites only measured the net radiation $\left(R_{\mathrm{n}}\right)$, rather than the four components of radiation separately, we approximated the incoming and outgoing radiation streams from the net radiation in order to calculate the associated entropy transport and production terms. In this formulation, the entropy transport terms associated with the LE, $H$ and $G$ are 
calculated from the measured fluxes. However, since there is no measured outgoing longwave radiation, a different formulation for the surface temperature was necessary. For this purpose, we derived the surface temperature by invoking Monin-Obukhov similarity theory from the air temperature, the heat flux and the local stability (Campbell and Norman, 1998):

$T_{0}=T_{\mathrm{a}}+\frac{H}{\kappa \rho c_{p} u_{*}}\left(\ln \left(\frac{z-d}{z_{m}}\right)+\psi_{H}\right)$

where $T_{0}$ is the aerodynamic temperature (i.e. the effective temperature controlling the sensible heat flux), $T_{\mathrm{a}}$ is the air temperature at the measurement height, $\kappa$ is the von Karman constant (0.4), $\rho$ is the air density, $c_{p}$ is the specific heat capacity, $z$ is the measurement height $(3 \mathrm{~m}), d$ is the displacement height ( $2 / 3$ height of canopy) and $z_{m}$ is the aerodynamic roughness length $((1 / 10) d)$.

Under unstable atmospheric conditions, the stability correction $\psi_{H}$ is assumed to be:

$\psi_{H}=-2 \ln \left(\frac{1+(1-16(z / L))^{1 / 2}}{2}\right)$

while for stable conditions:

$\psi_{H}=6 \ln (1+z / L)$

where $L$ is the Obukhov length.

The aerodynamic temperature is then used to compute the outgoing longwave radiation using the Stefan-Boltzmann Law assuming a constant surface emissivity of 0.9 (i.e. we assume that the aerodynamic and surface temperatures are identical).

The longwave emission from the atmosphere $\left(Q_{\mathrm{L}, \text { in }}\right)$ is calculated from the measured air temperature $\left(T_{\mathrm{a}}\right)$ using an empirical formulation (Brutsaert, 1975):

$Q_{\mathrm{L}, \text { in }}=0.552 e_{\mathrm{a}}^{(1 / 7)} \sigma T_{\mathrm{a}}^{4}$

where $e_{\mathrm{a}}$ is the actual vapor pressure in millibars.

The absorbed solar radiation is then computed from the net radiation equation as the difference between the measured $R_{\mathrm{n}}$ and the incoming and outgoing longwave radiant terms:

$Q_{\mathrm{S}}=R_{\mathrm{n}}+Q_{\mathrm{L}, \text { out }}-Q_{\mathrm{L}, \text { in }}$

with a minimum value of zero.

The use of the net radiation introduces a number of complications. First, the aerodynamic temperature is not the radiant surface temperature, but the two temperatures are related (e.g. Stewart et al., 1994). Secondly, any errors in the approximation of the radiant fluxes will impact the entropy production and transfer terms.

\section{Results}

\subsection{Surface entropy budget}

Prior to examining the impact of changes in the fractional vegetation cover, we investigated the variation in the entropy budget terms using the default forcing data and parameterization of the NOAH land surface model. This control run has a seasonal cycle to the fractional vegetation which reaches a maximum value of $96 \%$ coverage in August and a minimum value of $0.01 \%$ in January. The mean of the fractional vegetation is $34 \%$. In order to increase the ability to ascertain the relationships between different components of the energy fluxes and the associated entropy terms we focus on presenting the mean diurnal pattern of each variable.

Figure 2 displays the diurnal average pattern for the surface energy fluxes as well as the surface and air temperatures. The Bowen ratio shows a predictable diurnal pattern increasing to approximately 0.6 in the mid day.

Figure 3 shows the entropy production and transport terms associated with the radiation terms. As expected, the dominant entropy production is associated with the absorption of the solar radiation at the surface $\left(\sigma_{Q_{S}}\right.$, panel a) while the production due to absorption of longwave radiation is significantly smaller $\left(\sigma_{Q_{\mathrm{L}}}\right.$, panel c). The transport term due to longwave $\left(J_{Q_{\mathrm{L}}}\right.$, panel d) is of a much larger magnitude than that associated with the transport of shortwave radiation $\left(J_{Q_{S}}\right.$, panel b).

The transport entropy terms associated with the surface fluxes are shown in Fig. 4. The turbulent fluxes of LE and $H$ result in relatively large entropy transport rates, the entropy transport associated with the LE flux being about twice as high in the midday. The transport due to soil heat flux is generally smaller than that due to sensible heat flux during the day, with a more negative value at night.

The mean diurnal pattern of the entropy budget $(\mathrm{d} S)$ is shown in Fig. 4d. The entropy budget generally follows the pattern of solar radiation, as this is the dominant factor in the budget. The total hourly budget summed over the course of the $24 \mathrm{~h}$ is $0.97 \mathrm{~W} \mathrm{~m}^{-2} \mathrm{~K}^{-1}$.

\subsection{Impact of fractional vegetation changes on surface energy fluxes}

The impact of the change in fractional vegetation cover is explored next. Six simulations are conducted ranging from bare soil to $100 \%$ vegetation cover. For these simulations, the vegetation fraction is held constant throughout the year. For comparison with the previous section, recall that the mean of the vegetation cover was $34 \%$.

The resultant surface energy fluxes, Bowen ratio, surface temperature and net radiation are shown in Fig. 5. The latent heat flux demonstrates the most profound differences as a function of vegetation fraction with mean midday fluxes ranging between $227 \mathrm{~W} \mathrm{~m}^{-2}$ for fully vegetated 
(a)

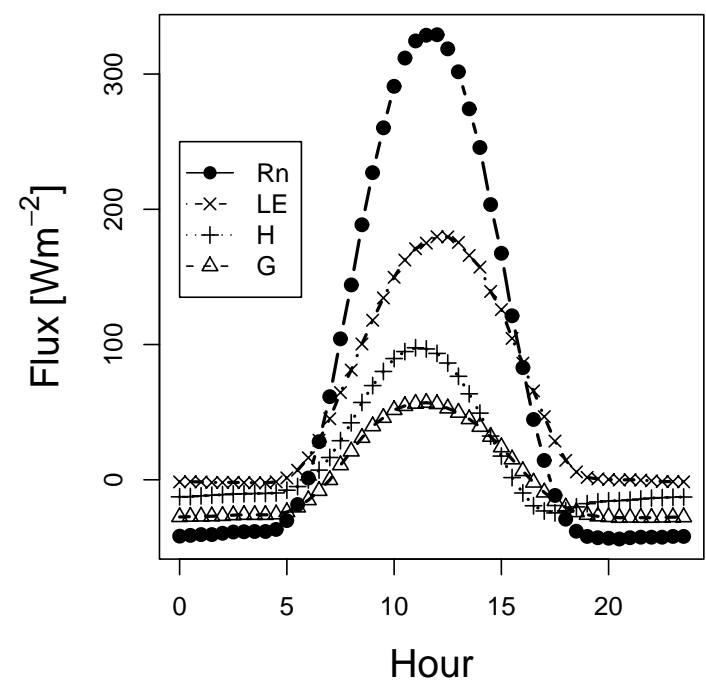

(b)

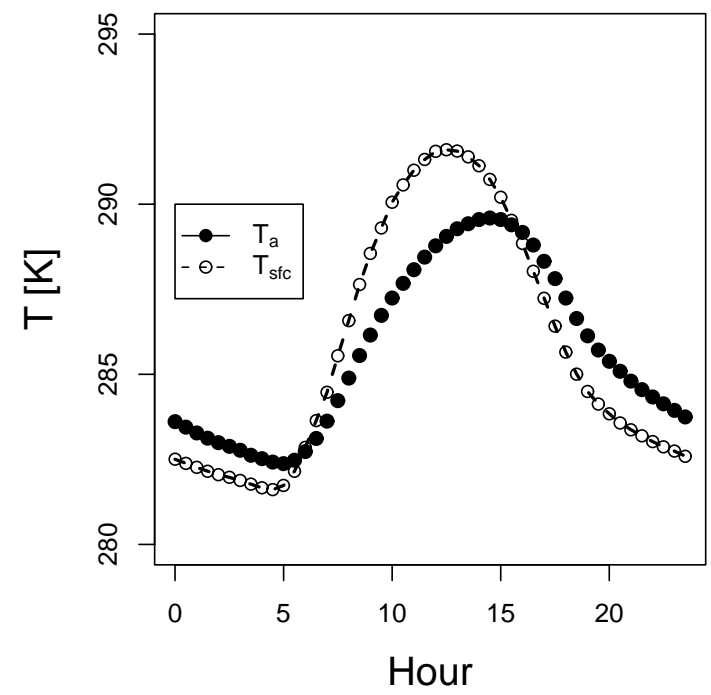

Fig. 2. Mean diurnal (a) surface energy fluxes and (b) surface and air temperatures for the control model run.

to $118 \mathrm{~W} \mathrm{~m}^{-2}$ in the bare soil case. There was little change in the $R_{\mathrm{n}}$ which had midday values which varied between $324 \mathrm{~W} \mathrm{~m}^{-2}$ and $290 \mathrm{~W} \mathrm{~m}^{-2}$ for the full coverage and bare soil respectively (Fig. 5f). The additional flux of latent heat is taken at the expense of the sensible (ranging between 89 and $117 \mathrm{~W} \mathrm{~m}^{-2}$ ) and soil heat ( 16 to $87 \mathrm{~W} \mathrm{~m}^{-2}$ ) fluxes. This change in energy balance partitioning is easily observed in the mean diurnal pattern of the Bowen ratio, which ranges between 0.89 in the bare soil simulation down to 0.39 in the fully vegetated case (panel d).

The mean diurnal pattern of net radiation shows very little variation as a function of vegetation fraction. The downward radiation components do not change, the prescribed albedo variation as a function of vegetation cover varies from 0.18 to 0.25 , causing the reduction in absorption of solar radiation with increasing bare soil. This leads to a small impact on surface temperature (Fig. 5e), which has a similar impact on the longwave radiation emitted by the surface.

As a result of the changes in the evaporative flux, there is an expected reduction in volumetric soil moisture with increasing vegetation. The mean soil moisture in the top $10 \mathrm{~cm}$ decreases from $0.35 \mathrm{~m}^{3} \mathrm{~m}^{-3}$ in the bare soil simulation down to $0.30 \mathrm{~m}^{3} \mathrm{~m}^{-3}$ in the full vegetation scenario. In addition to the lower mean values, higher vegetation cover corresponds with a higher rate of water use during a "dry-down" event which occurs between days 200 and 260 (not shown).

\subsection{Fractional vegetation impacts on the surface entropy budget}

Next we examine the variation in the entropy transport and production terms due to the changes in the fractional vegetation cover.
In general, these terms follow similar dynamics to the surface energy fluxes. The entropy production due to the absorption of radiation is also presented in Fig. 6. Again, the production associated with the absorption of the short wave radiation $\left(\sigma_{Q_{\mathrm{S}}}\right)$ is the largest component. This is due to the fact that it represents to a large extent the transformation of energy from the solar radiation (high temperature) to lower temperature terrestrial processes. The midday values increase as a function of vegetation cover, increasing from 1.16 to $1.26 \mathrm{~W} \mathrm{~m}^{-2} \mathrm{~K}^{-1}$. The entropy production due to absorption of longwave radiation $\left(\sigma_{Q_{\mathrm{L}}}\right)$ at the surface shows little variation during the daylight hours. However, at night the higher vegetation content is accompanied by a slightly reduced value of the entropy production, but note that this term is significantly smaller than the production due to the absorption of solar radiation. Nighttime hours also correspond to variation in the entropy transport related to longwave radiation $\left(J_{Q_{\mathrm{L}}}\right)$.

The changes in the surface entropy budget terms are associated with changes in the associated fluxes. As expected, the latent heat flux causes the largest entropy transfer (Fig. 7a). The entropy transfer due to LE is approximately double those associated with the sensible and ground heat fluxes. As vegetation fraction is increased, the associated entropy transfer term increases from 0.40 to $0.76 \mathrm{~W} \mathrm{~m}^{-2} \mathrm{~K}^{-1}$ for the midday values.

From the component entropy terms, the overall entropy budget of the surface can be calculated from Eq. (11). Figure $7 \mathrm{~d}$ illustrates the clear relationship between entropy budget as a function of vegetation fraction. Whereas the production terms are primarily associated with the variation in shortwave radiation, the impacts of the vegetation cover on the entropy budget is most clearly seen in the nighttime hours. 
(a)

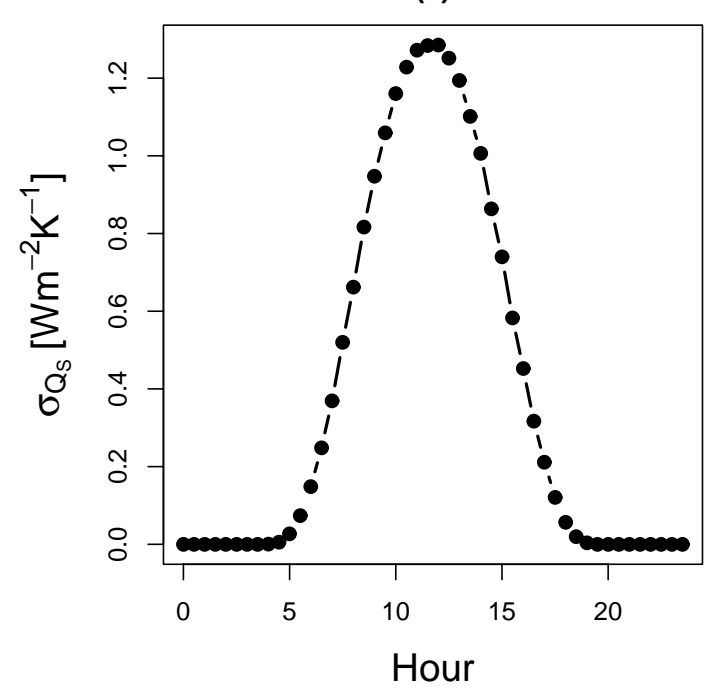

(c)

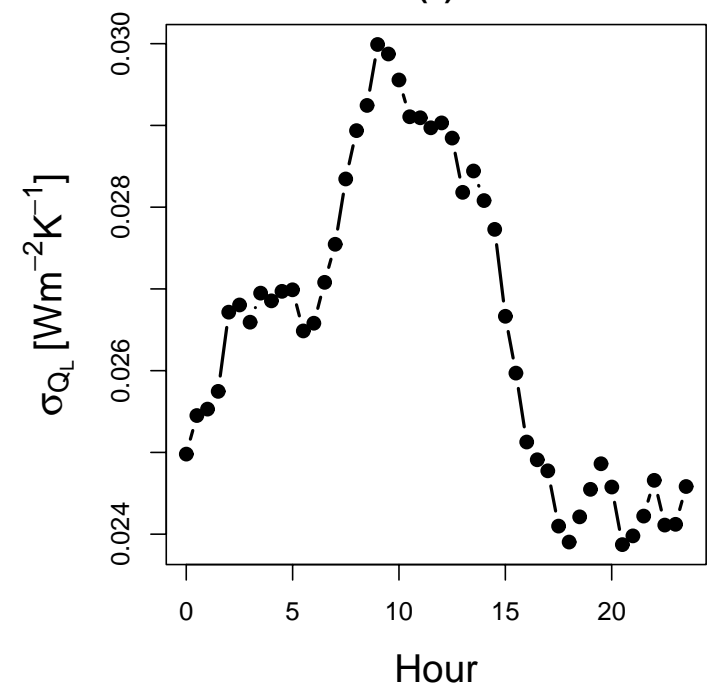

(b)

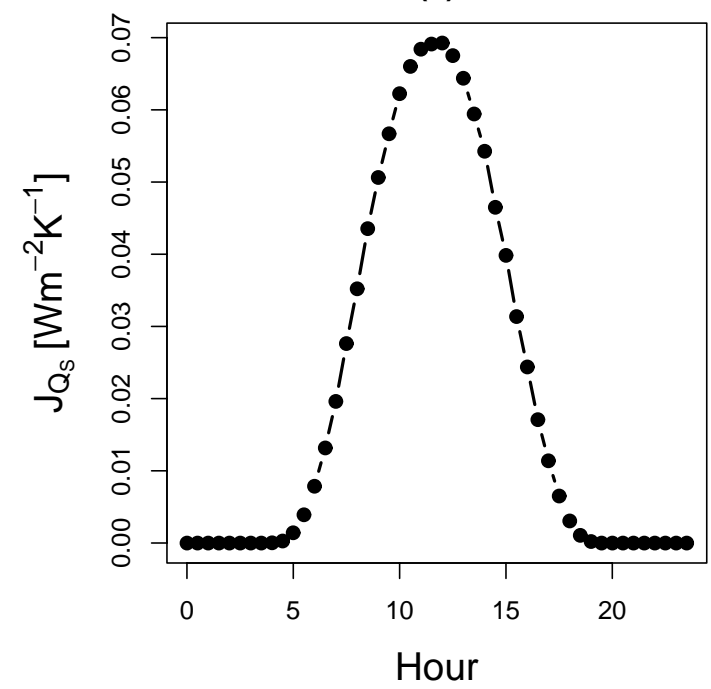

(d)

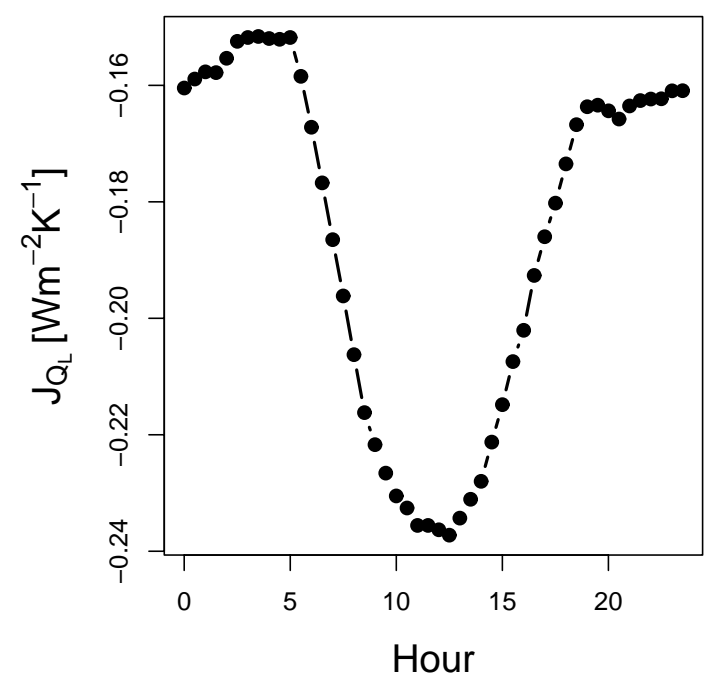

Fig. 3. Mean diurnal entropy terms associated with (a) production due to to conversion of shortwave radiant energy, (b) transport due to shortwave radiation (c) production due to longwave radiant exchange and (d) transport associated with longwave radiation.

In these hours, as the vegetation fraction increases, there is a reduction in the total entropy budget due to the effects of the entropy transport related to the soil heat and sensible heat fluxes.

The effect of increasing vegetation cover is to decrease the total entropy budget, which is achieved by increasing the entropy transfer associated primarily with the soil heat flux. The sum of the production terms over the daily cycle is presented in Fig. 8a. There is a clear linear trend showing the increase in entropy production with increasing fractional vegetation cover. However, the summation of the total overall entropy budget decreases with increasing vegetation fraction as shown in Fig. 8b.

\subsection{Application to eddy covariance observations}

The previous results show the impacts of vegetation cover on both the energy and entropy budgets in a physically-based model. However, it remains to be seen to what extent the entropy budget is a useful tool when considering actual observations. Therefore, the final stage of this analysis was to apply the thermodynamic entropy calculations to the observed fluxes at three different sites, two having a similar climate but different fire regimes (KZU being burnt annually, while K4B being burnt at a 4-year cycle) and one site representing the succession of a maintained grass land after being excluded from land use (KFS). 
(a)

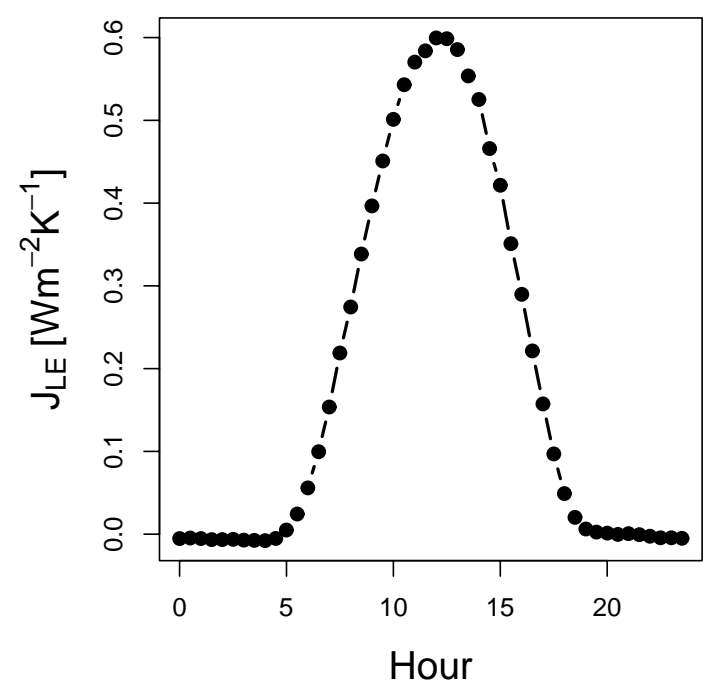

(c)

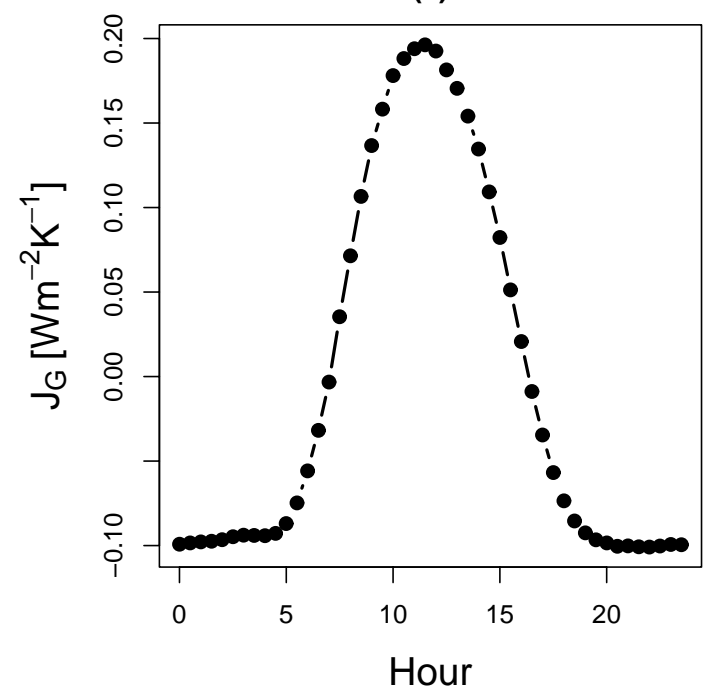

(b)

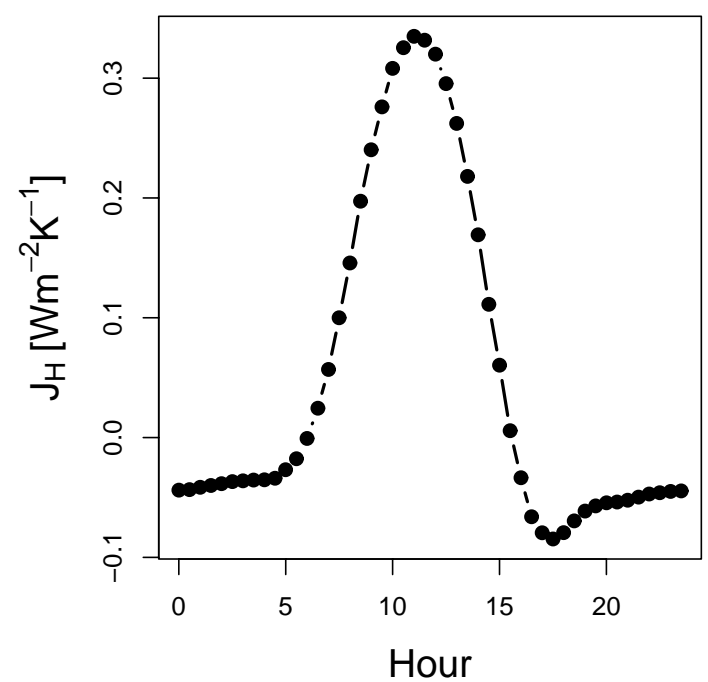

(d)

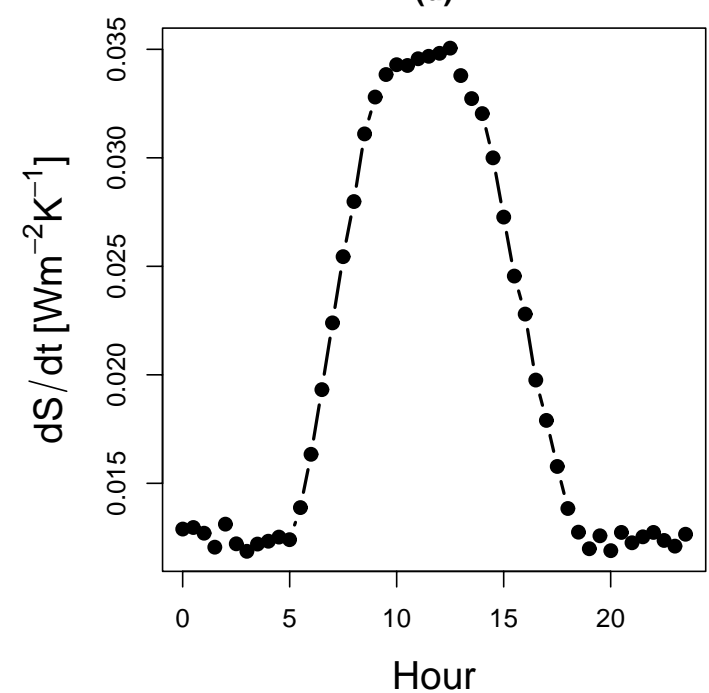

Fig. 4. Mean diurnal entropy terms associated with (a) transfer due to latent heat flux (b) transfer due to sensible heat flux (c) transfer due to soil heat flux and (d) the overall entropy budget.

At each of the sites, the diurnal variability associated with the measured fluxes are shown in Fig. 9. There was a slight variation in the net radiation between the sites, with $\mathrm{K} 4 \mathrm{~B}$ having a slightly higher value and KZU having the lowest. There was a higher latent heat flux observed at the KFS site while a larger sensible heat flux was seen at the K4B site. This leads to a variation in the Bowen ratio between the sites. In addition, the mean air temperature and surface temperature are shown for each site with a consistent trend of KFS being slightly cooler, while K4B being the warmest site.

The entropy terms from the three sites are calculated in the same manner as the land surface model output (Fig. 10), with the measured $R_{\mathrm{n}}$ being used to estimate the component radiative fluxes. Similar to the model results, the largest value is associated with the production of entropy due to the conversion of shortwave radiation $\left(\sigma_{Q_{\mathrm{S}}}\right)$. The entropy production due to longwave absorption is shows a clear trend between the sites, with K4B having a higher value and KFS exhibiting lower values. The KFS site has a more negative transport term from longwave radiation in the late morning hours compared to the sites at Konza Prairie.

The variation in surface fluxes leads to the same variation in the entropy terms (Fig. 11). Here, KFS has a slightly higher values for the entropy transport associated with both the latent heat and soil heat fluxes during the peak of the day, followed by K4B and with KZU having the smallest absolute 
(a)

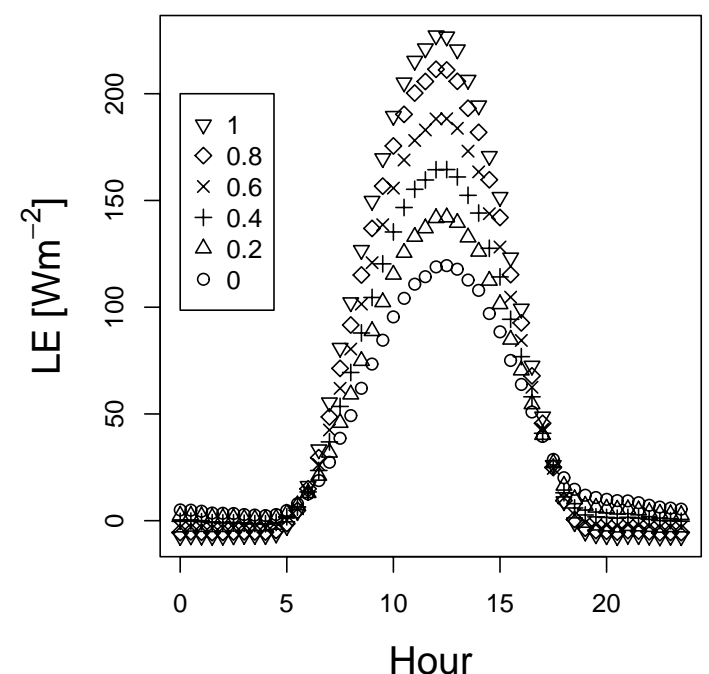

(c)

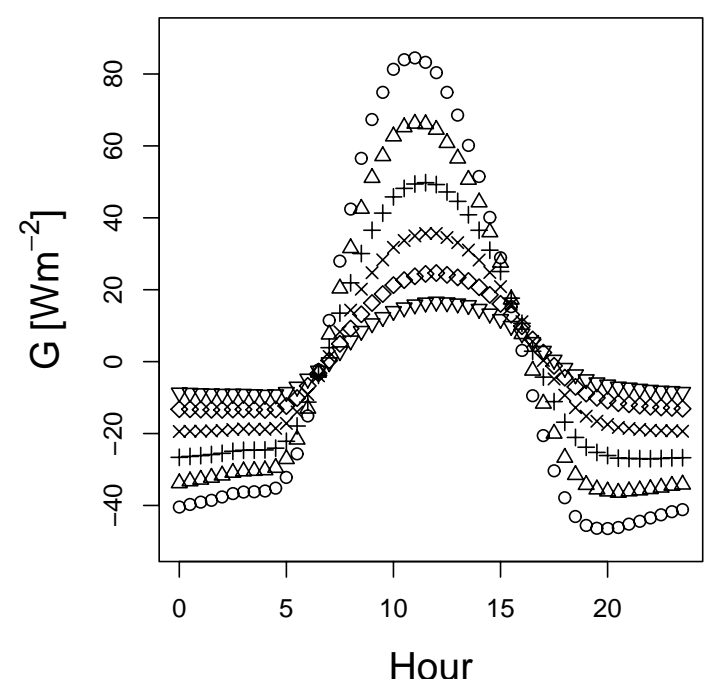

(e)

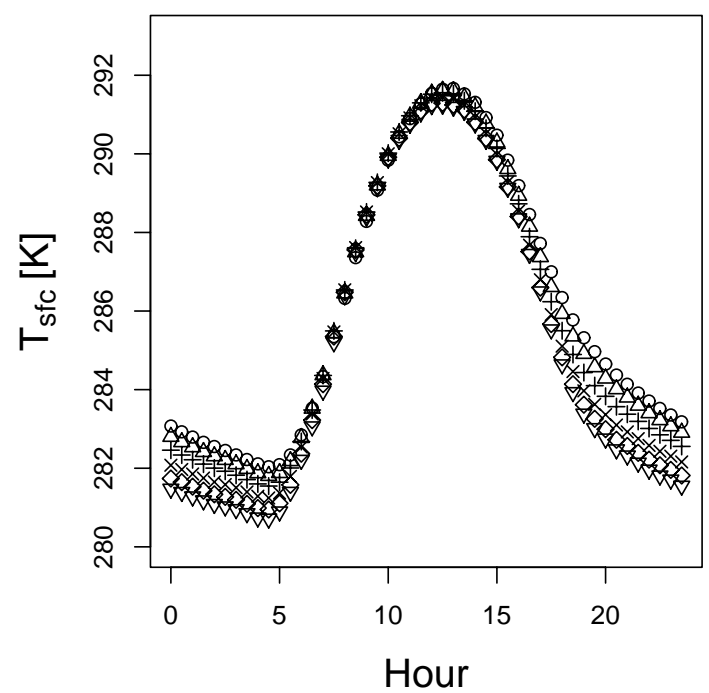

(b)

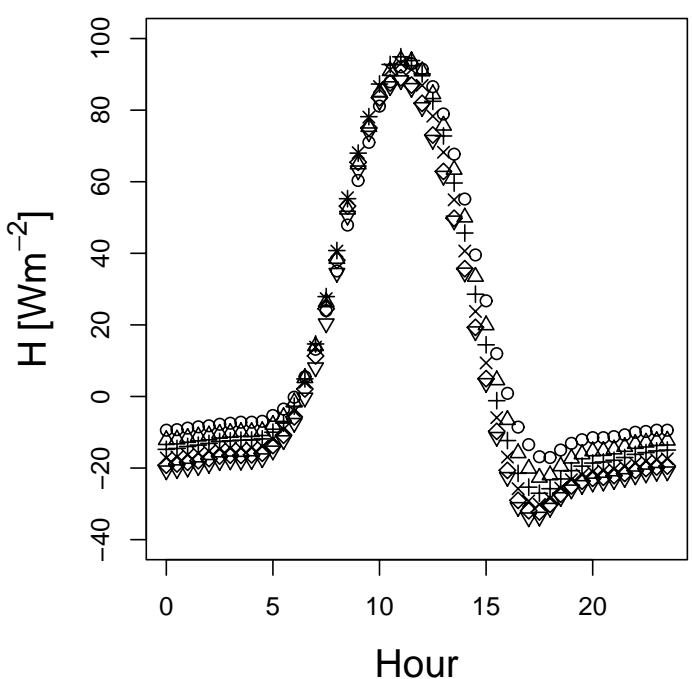

(d)

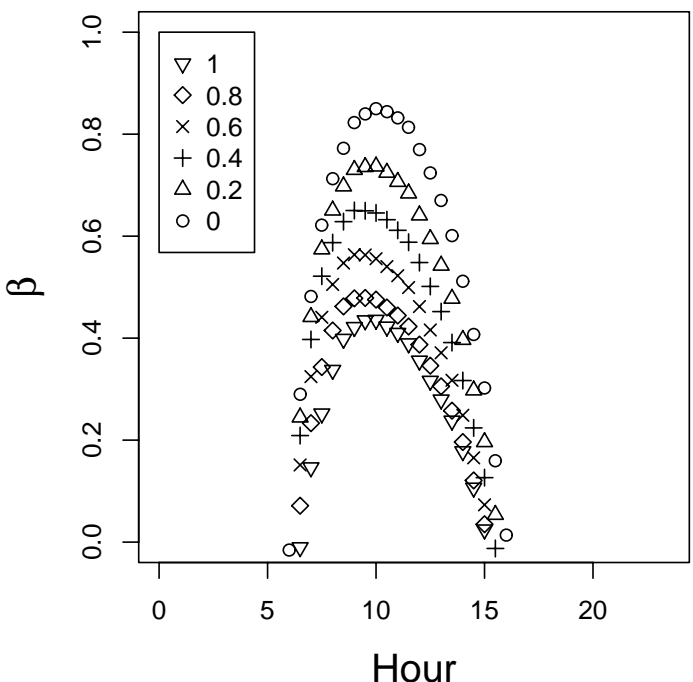

(f)

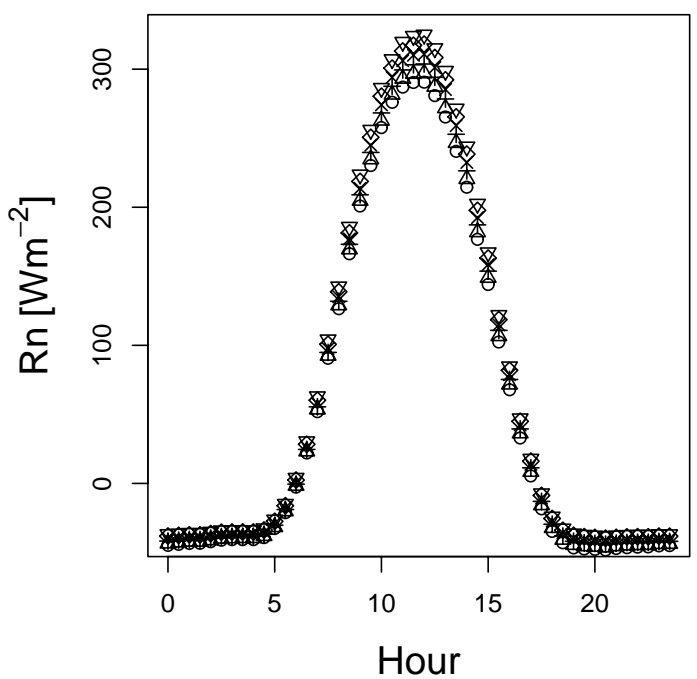

Fig. 5. Mean diurnal variability of (a) latent heat flux (b) sensible heat flux (c) soil heat flux (d) Bowen ratio ( $\beta=H / L E)(e)$ surface temperature and (f) net radiation as a function of vegetation fractional cover. 
(a)

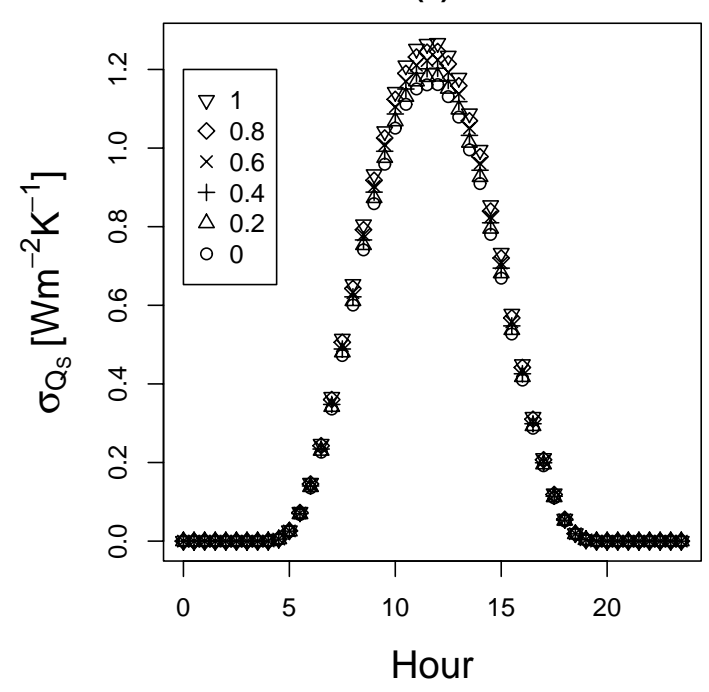

(c)

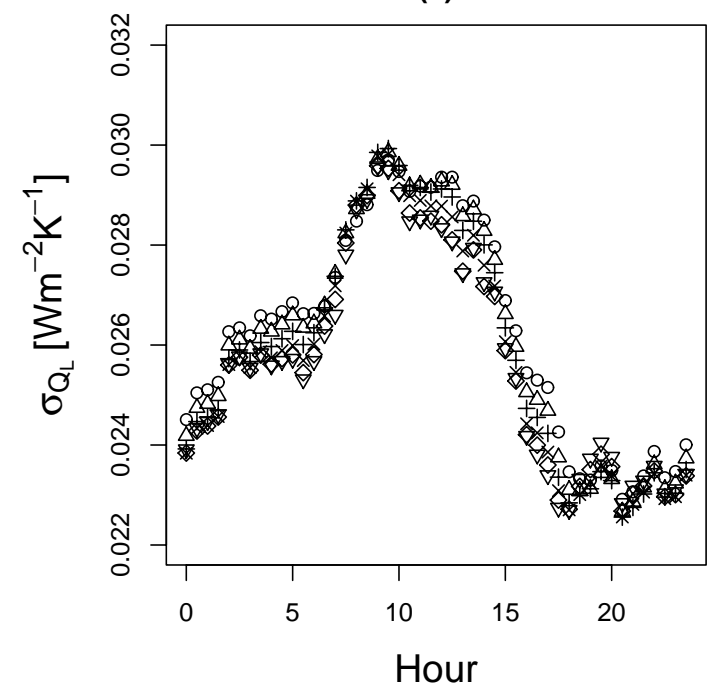

(b)

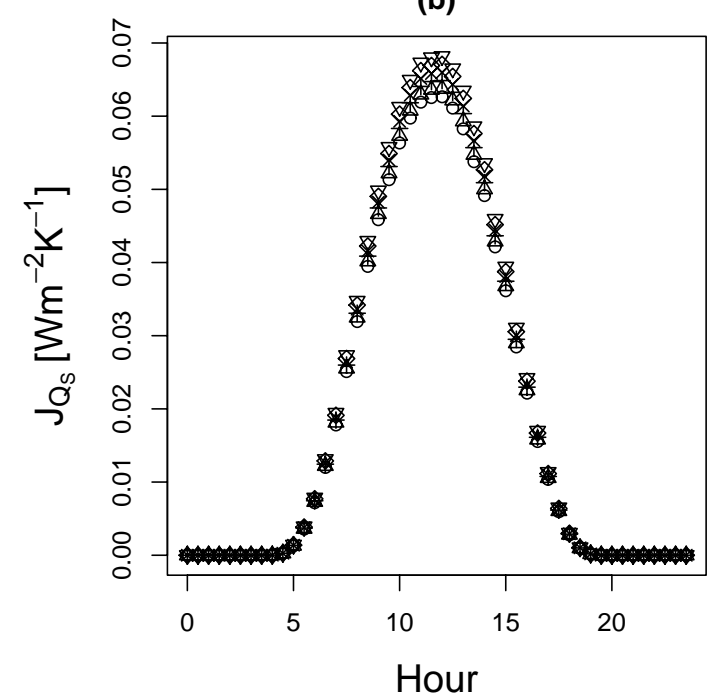

(d)

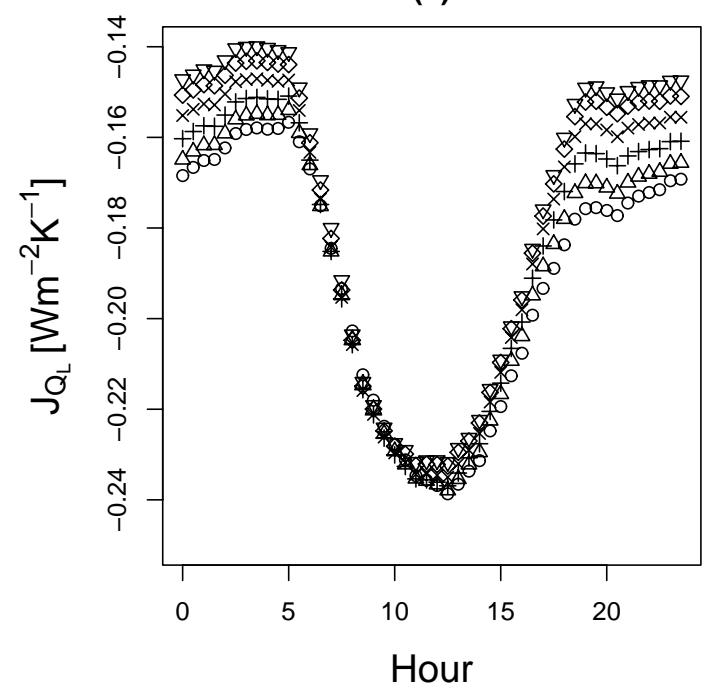

Fig. 6. Mean diurnal entropy terms associated with (a) production due to to conversion of shortwave radiant energy, (b) transport due to shortwave radiation (c) production due to longwave radiant exchange and (d) transport associated with longwave radiation as a function of fractional vegetation cover.

value. The K4B site has a higher value of transport entropy associated with the sensible heat flux.

The overall entropy budget is shown in Fig. 11d. The K4B site has a reduced peak at midday relative to the other sites. KZU shows a phase shift towards earlier hours. Note that the overall values observed here are approximately a factor of ten larger than those in the NOAH model, as seen by comparison with Fig. 7. In addition, note that the total budget from the observations is negative at nighttime, while for the model results this value was always positive. One likely explanation for this is that in the model, the air temperature and other fields are decoupled from the surface conditions.
This implies that the surface is simply responding to the imposed atmospheric state. However, in reality, the different land cover types create their own microclimatic conditions and thus alter the transfer of energy into the turbulent fluxes as well as alter the near surface atmospheric conditions.

The variation in the sites is maintained in the total daily summations, with $\mathrm{K} 4 \mathrm{~B}$ exhibiting the smallest value $\left(5.21 \mathrm{~W} \mathrm{~m}^{-2} \mathrm{~K}^{-1}\right)$, then the KFS site $\left(5.39 \mathrm{~W} \mathrm{~m}^{-2} \mathrm{~K}^{-1}\right)$ and finally KZU $\left(5.64 \mathrm{~W} \mathrm{~m}^{-2} \mathrm{~K}^{-1}\right)$. Given that the $\mathrm{KZU}$ and $\mathrm{K} 4 \mathrm{~B}$ sites are located approximately $1 \mathrm{~km}$ apart from one another, it was assumed that the microclimates were similar between the sites. In addition, the values of total entropy 
(a)

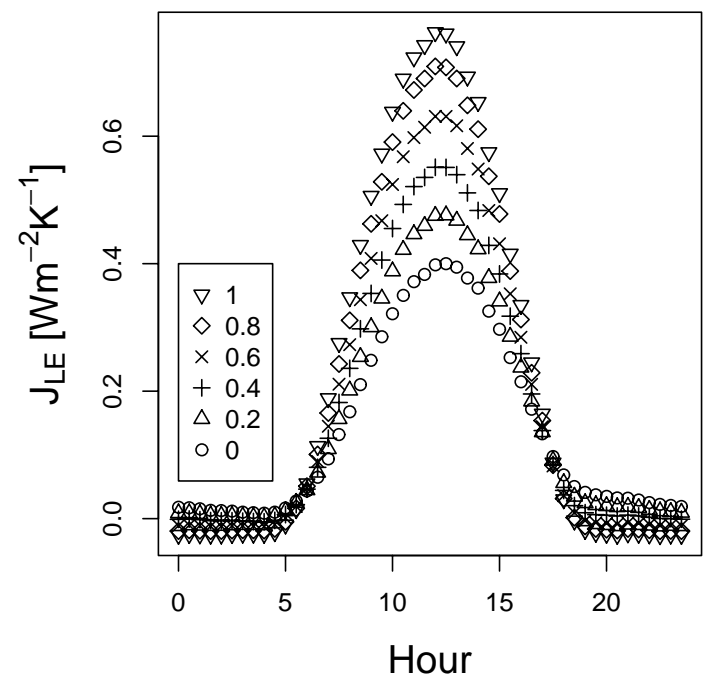

(c)

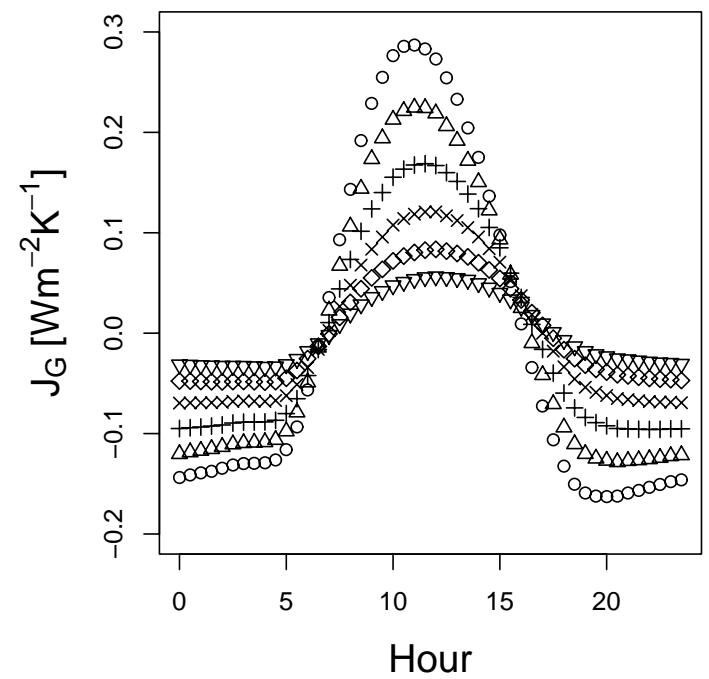

(b)

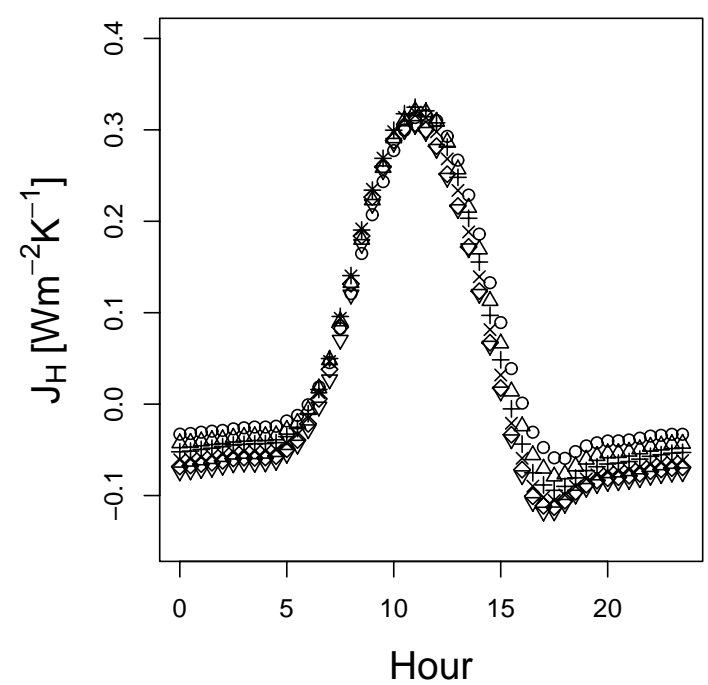

(d)

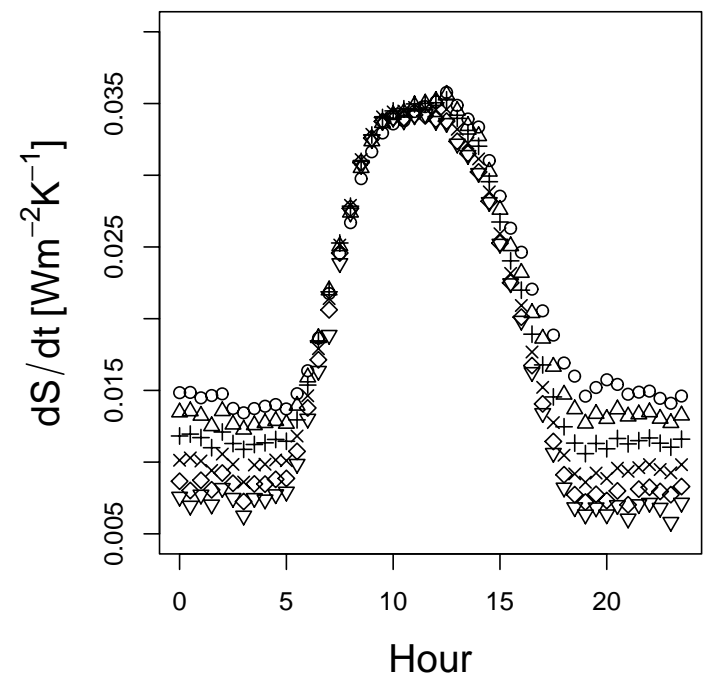

Fig. 7. Mean diurnal entropy terms associated with (a) transfer due to latent heat flux (b) transfer due to sensible heat flux (c) transfer due to soil heat flux and (d) the overall entropy budget as a function of fractional vegetation cover.

production $(\sigma)$ for each site was $23.81 \mathrm{~W} \mathrm{~m}^{-2} \mathrm{~K}^{-1}$ for $\mathrm{K} 4 \mathrm{~B}$, $24.35 \mathrm{~W} \mathrm{~m}^{-2} \mathrm{~K}^{-1}$ for KFS and $23.60 \mathrm{~W} \mathrm{~m}^{-2} \mathrm{~K}^{-1}$ for KZU. The mean standard deviation of the half hour entropy budget is somewhat large; for $\mathrm{K} 4 \mathrm{~B}$ the value was $0.20 \mathrm{~W} \mathrm{~m}^{-2} \mathrm{~K}^{-1}$, for KFS the value was $0.18 \mathrm{~W} \mathrm{~m}^{-2} \mathrm{~K}^{-1}$, and for $\mathrm{KZU}$ the value was $0.31 \mathrm{~W} \mathrm{~m}^{-2} \mathrm{~K}^{-1}$.

Since the flux partitioning is different and the total entropy budget is different, we examined the mean diurnal pattern of air temperature (Fig. 9). The K4B site has a higher average air temperature by approximately $0.5^{\circ} \mathrm{C}$. While this may appear to be insignificant, it does lead to variation in the flux partitioning strategies of the two sites, even given similar values of net radiation.
In the case of the vegetation fraction model runs, there was a clear relationship between the vegetation fraction, Bowen ratio, entropy production and total entropy budgets. However, when applied to the field observations, the ordering of the sites was not maintained across all variables. For example, the air temperature and Bowen ratio had an order of K4B - KZU - KFS from high to low. However, the entropy production was ordered KFS - K4B - KZU and the total entropy was KZU - KFS - K4B. The ordering of the midday $R_{\mathrm{n}}$ values was the reverse of the total entropy: K4B - KFS KZU. This suggests that the overall entropy seems to be related to the net radiation more closely than to any other variable, while the entropy production appears to be unrelated 
(a)

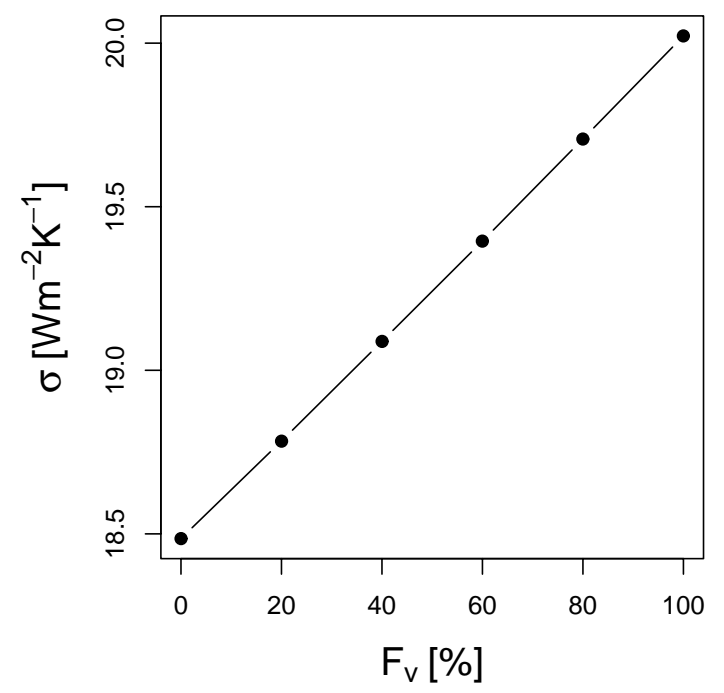

(b)

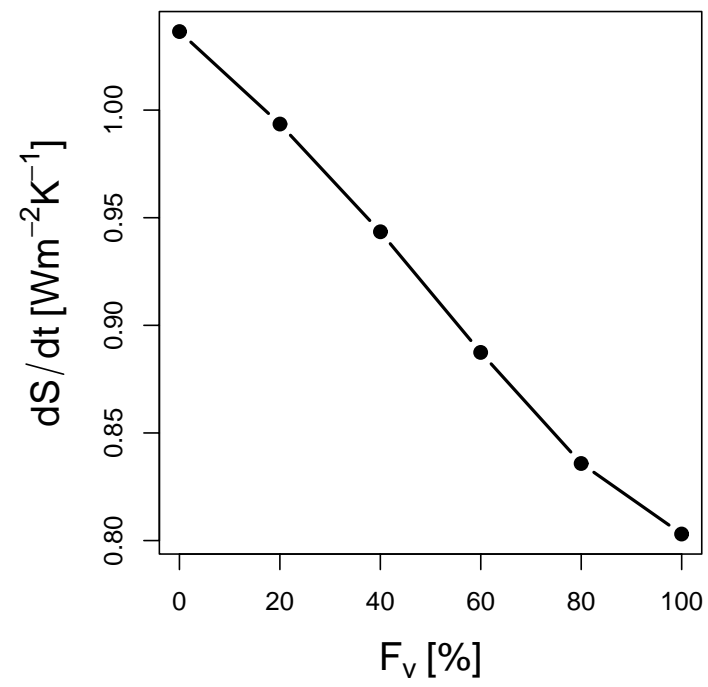

Fig. 8. Values of (a) entropy production and (b) overall entropy budget summed over the diurnal cycle as a function of fractional vegetation cover.

to any particular variable and we therefore conclude that this is a reflection of the land cover and the land use histories of these sites. This has to be confirmed in a follow-up study using more sites with known land cover and land use histories.

\section{Conclusions}

This set of land surface model simulations implies that the role of vegetation is to increase the entropy production by altering the absorption of solar radiation and decreasing surface temperature. At the same time, vegetation increases the entropy transfer associated with the latent heat flux. This dynamic is observed even with minimal change in the net radiation at the surface, implying a change in the energy balance partitioning. This is confirmed through an examination of the Bowen ratio in each case.

Observational evidence such as LeMone et al. (2007) have found similar results when assessing the roles of vegetation heterogeneity on partitioning of surface fluxes. LeMone et al. (2007) examined field results in Kansas and found that the $R_{\mathrm{n}}$ was relatively constant across both sparse and fully vegetated areas. However, the partitioning of LE was higher in the vegetated areas. Furthermore, they found that this alteration of energy balance partitioning was sensitive to precipitation dynamics. Modeling results from Jones and Brunsell (2009) showed that this partitioning of energy balance fluxes plays a significant role on controlling the positive soil moisture precipitation feedback in the region.
Thus, vegetation appears to increase the entropy production through the conversion of shortwave radiation to heat. At the same time, vegetation clearly increases the entropy export dominated by the latent heat transfer during the daytime and soil and sensible heat fluxes during the nighttime hours. This leads to a decrease of the overall entropy budget when compared to the model runs with reduced vegetation cover.

This alteration of the local energy balance partitioning has a large impact on the nature of the entropy transfer and entropy budget of the land surface. Increasing values of vegetation fraction resulted in increases in the entropy production and a decrease in the total entropy budget. This is consistent with the results of Tesar et al. (2007) who showed an increase in the entropy exchange associated with latent heat flux for a vegetated surface compared to a bare soil surface. This is also consistent with Kleidon $(2004,2007)$ who found increasing vegetation cover resulted in higher entropy production within the framework of the maximum entropy production hypothesis.

However, when we extend the analysis to compute the entropy budget from eddy covariance observations, the relationship becomes more complex. Here, the entropy production and the overall entropy budget rank the sites in different orders. The overall entropy appears most related to variation in $R_{\mathrm{n}}$ across the sites, implying that current land cover can provide insight into the overall entropy. The ranking of entropy production was not seen in the other micrometeorological fields, and suggests that land cover disturbance history may be the driving factor on entropy production. 
(a)

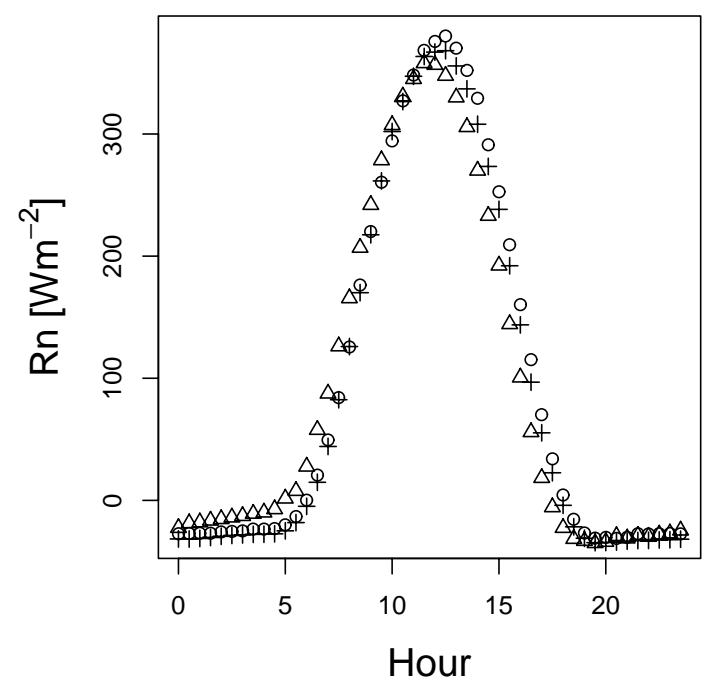

(c)

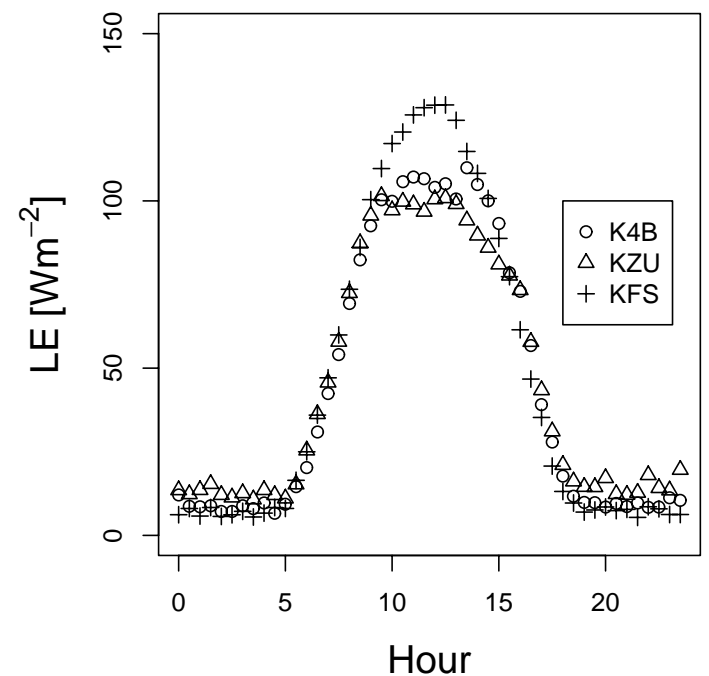

(e)

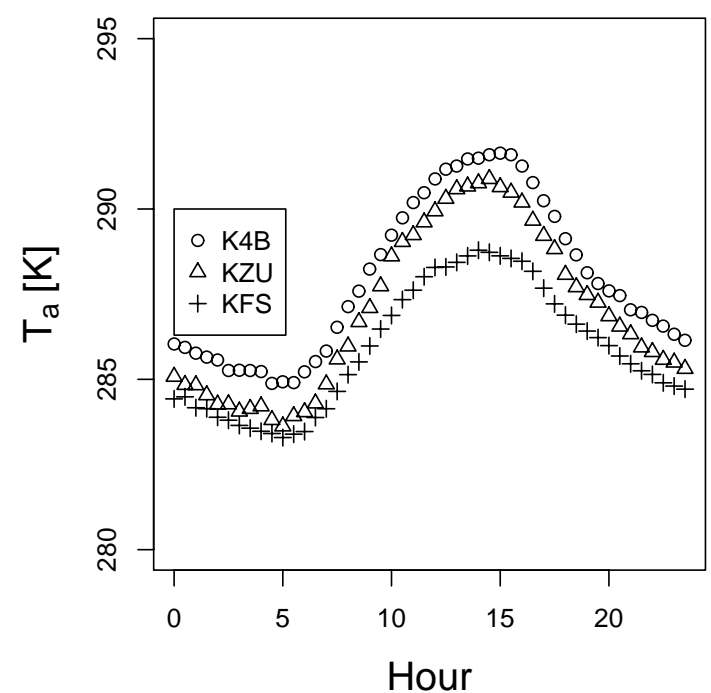

(b)

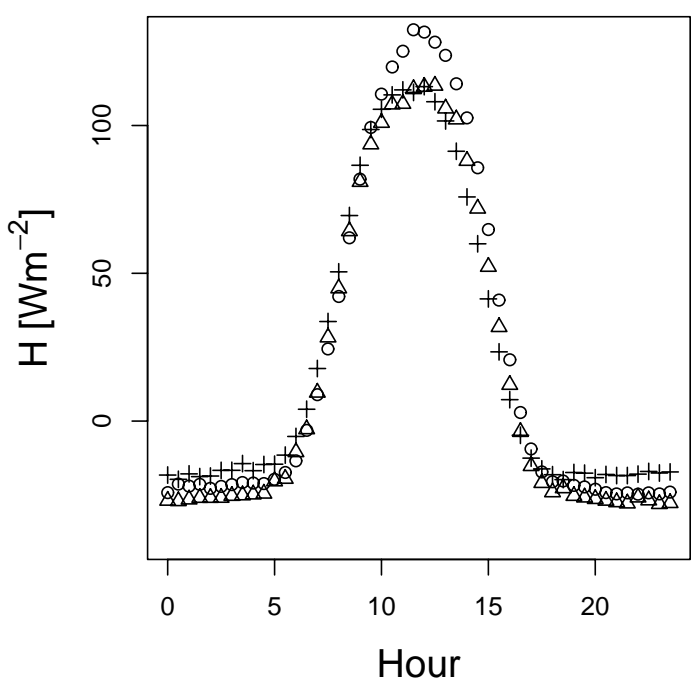

(d)

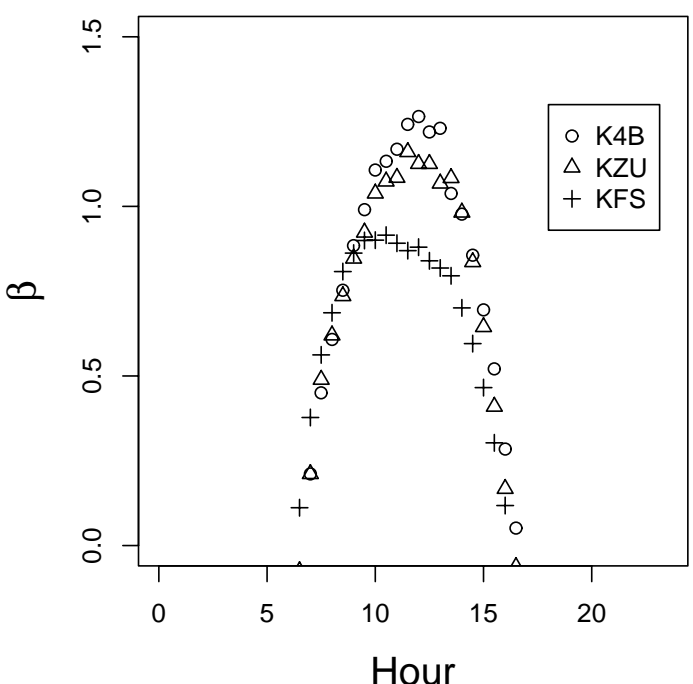

(f)

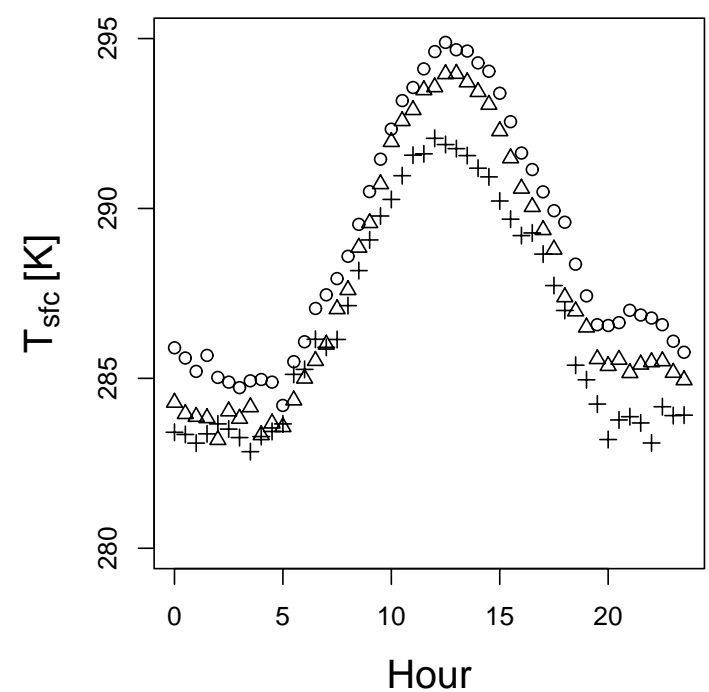

Fig. 9. Mean diurnal variability of (a) net radiation (b) sensible heat flux (c) latent heat flux (d) Bowen ratio $(\beta=H / \mathrm{LE})(\mathbf{e})$ air temperature and (f) the surface temperature from the eddy covariance data at each of the field sites. 
(a)

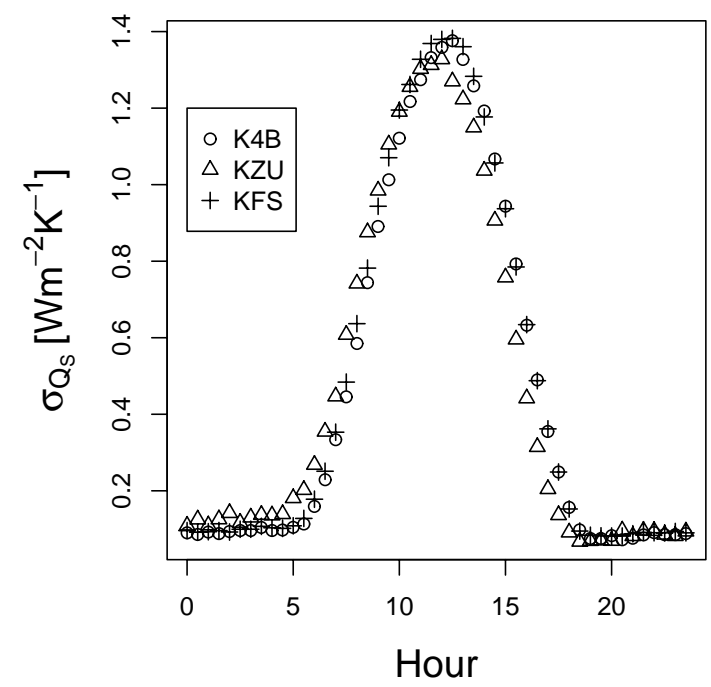

(c)

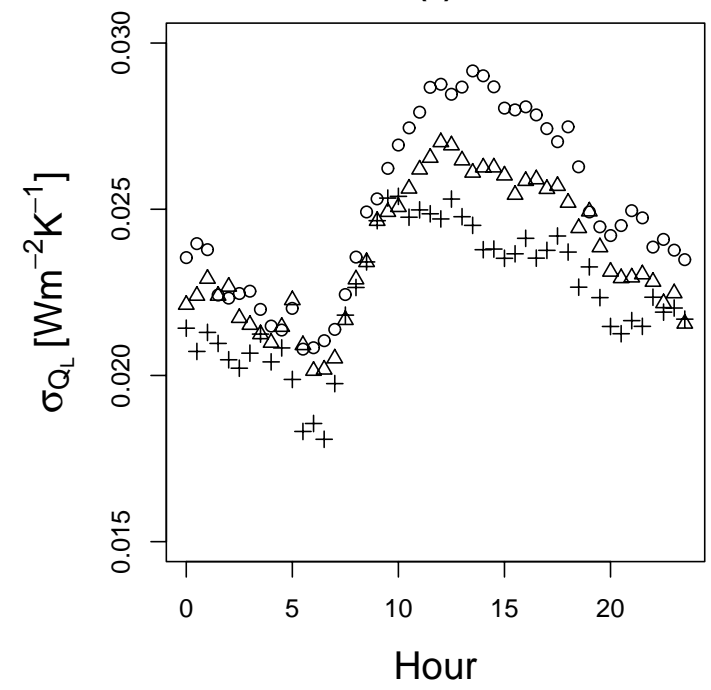

(b)

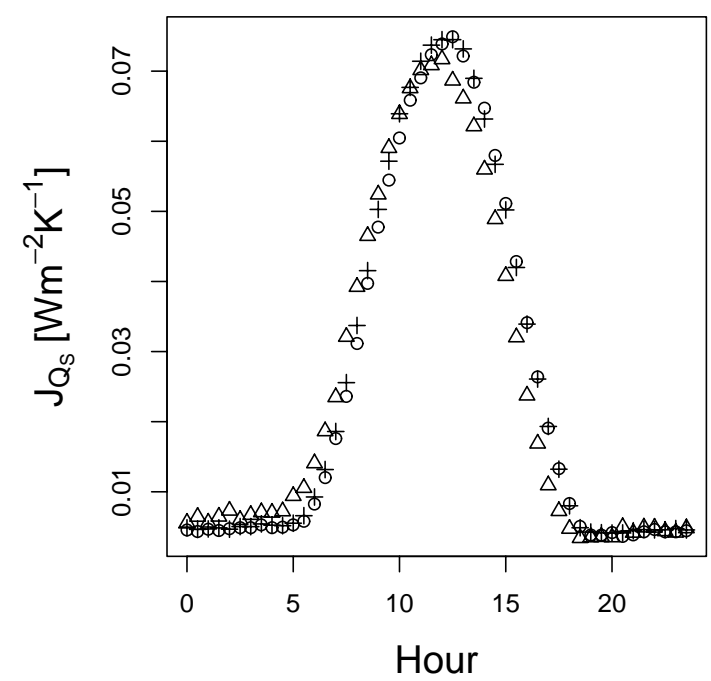

(d)

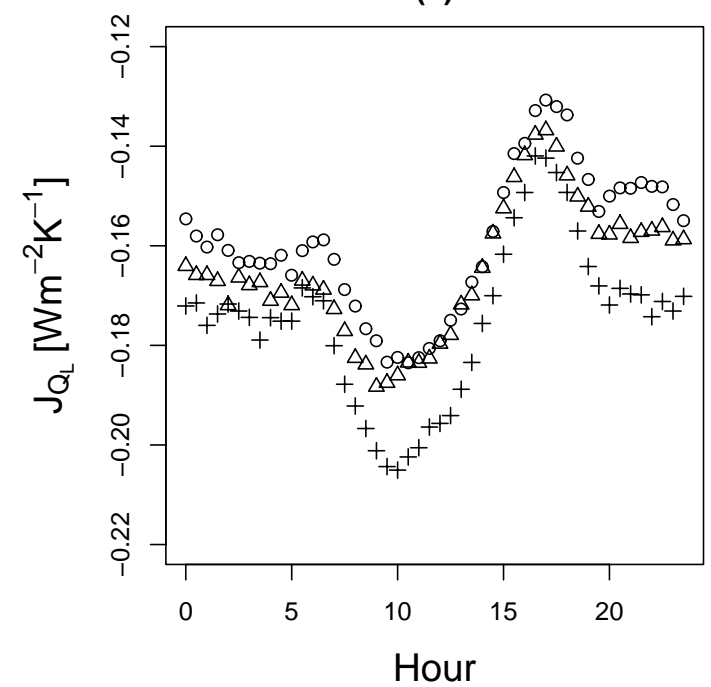

Fig. 10. Mean diurnal entropy terms associated with (a) production due to to conversion of shortwave radiant energy, (b) transport due to shortwave radiation (c) production due to longwave radiant exchange and (d) transport associated with longwave radiation computed from the eddy covariance data.

This implies that the use of the second law of thermodynamics might be a useful tool for examining eddy covariance observations. Given the rise of eddy covariance networks such as FLUXNET, these measurements provide some of the highest quality observations of radiative and turbulent fluxes available. A potential problem with the examination of entropy budgets from eddy covariance observations is that it is difficult to incorporate information from above the surface layer (e.g. boundary layer height and higher atmospheric properties) from these observations. This necessitates confining the system to the surface as opposed to including the atmosphere in the system. This potentially also limits the application of eddy covariance observations to assessing the maximum entropy production hypothesis, which is usually suggested to apply to the total surface-atmosphere system in steady state (Ozawa and Ohmura, 2010).

This study is also supportive of the idea of using entropy production as a measure of ecological succession (Holdaway et al., 2010) and more generally as a measure of ecological sustainability (Patzek, 2008). Assessing the relationship between entropy production during ecological succession and the maximum entropy production hypothesis for determining different steady state configurations will require additional study. 
(a)

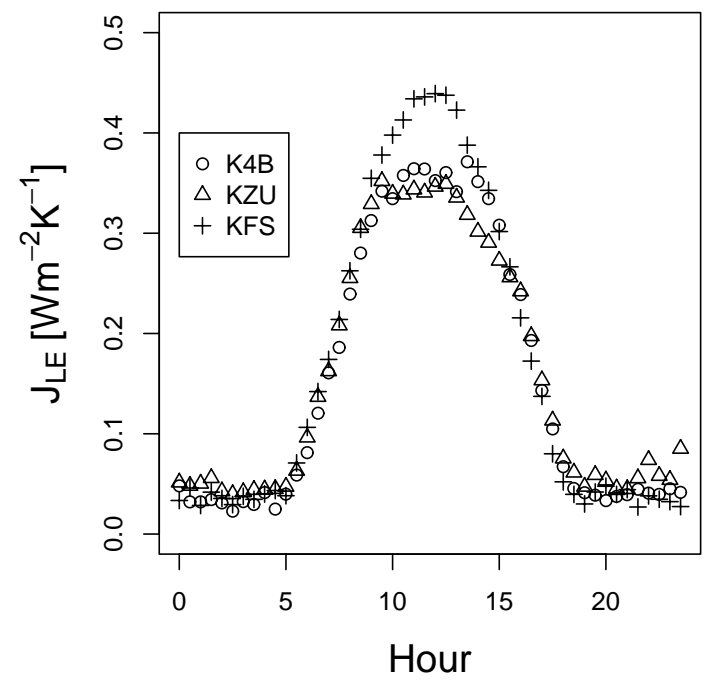

(c)

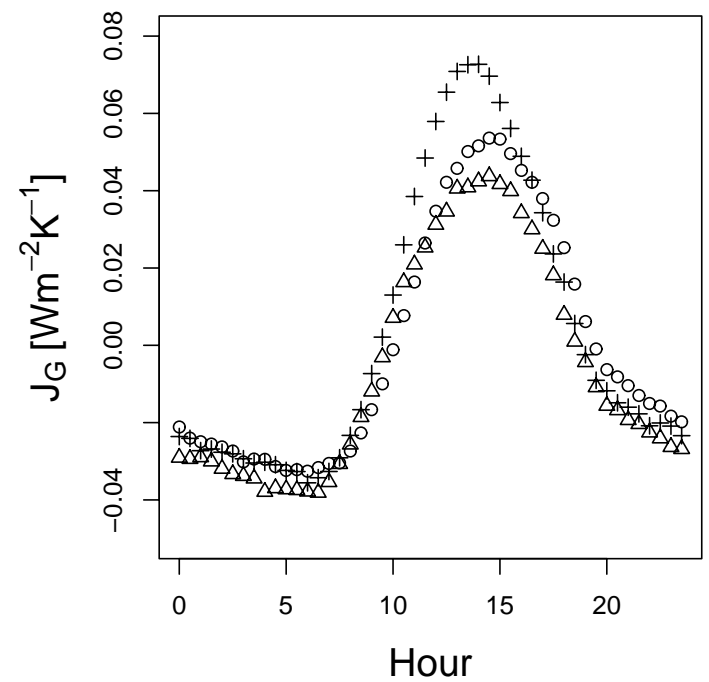

(b)

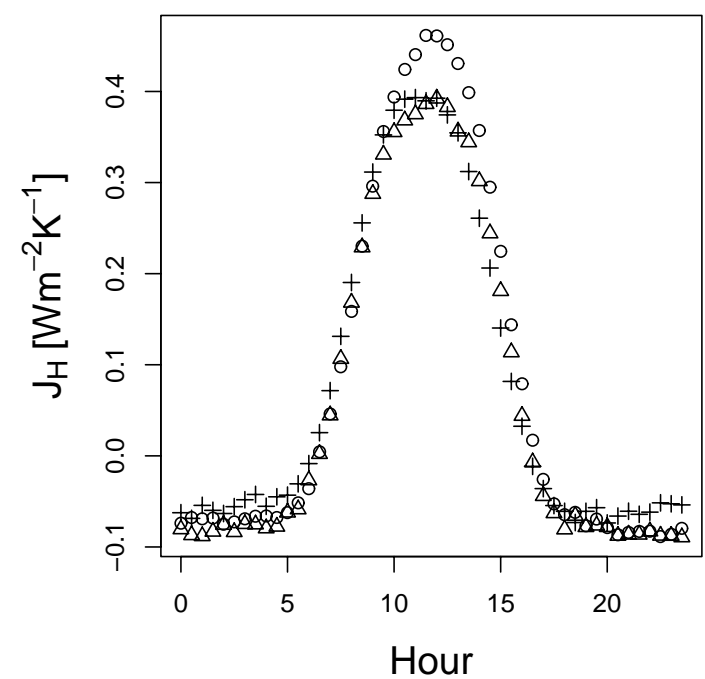

(d)

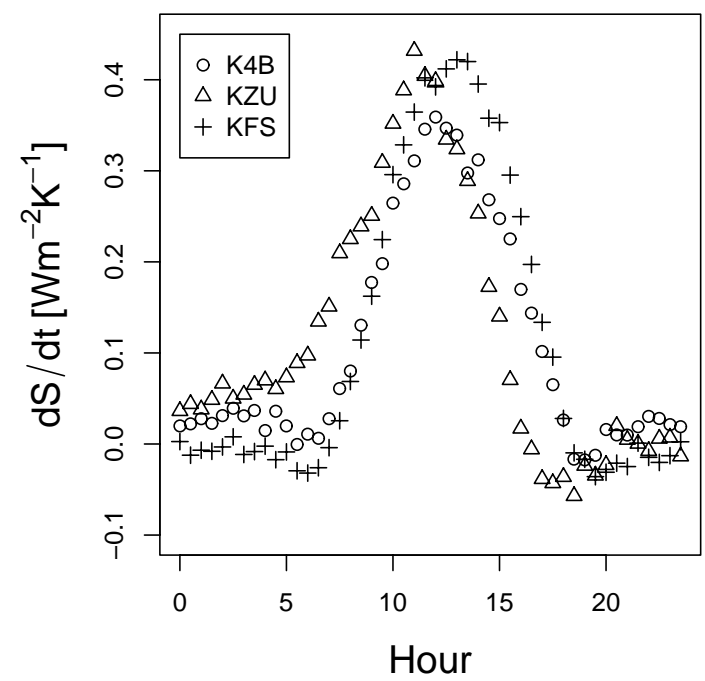

Fig. 11. Mean diurnal entropy terms associated with (a) transfer due to latent heat flux (b) transfer due to sensible heat flux (c) transfer due to soil heat flux and (d) the overall entropy budget computed from the eddy covariance data.

These results are supportive of using thermodynamic entropy as a measure of biogeographic variability. We were able to show in a numerical experiment, that both the entropy production and the overall entropy budget are sensitive to land cover variability. The model results indicate that both the entropy production as well as the overall entropy budget are useful measures for assessing the variation in land-atmosphere exchange processes. In addition, we found that comparison of the entropy production of the two sites with different fire regimes would allow identification of the more disturbed site, which was not revealed by the Bowen ratios or the energy budgets of these sites. Thus we agree with Patzek (2008), Svirezhev (2000) and Steinborn and Svirezhev (2000) that quantifying the entropy production is potentially useful for detecting land cover change and disturbance. Given the simplicity of the methodology applied in this paper and the large standard deviations in the observations, we recommend the analysis be repeated with a larger number of eddy flux sites with various land cover types as well as various levels of disturbance in order to examine how consistently the entropy budget identifies disturbed sites. 
Acknowledgements. We wish to thank the three reviewers for their comments. This research was supported through a fellowship from the Alexander von Humboldt Stiftung/Foundation awarded to NAB to support a sabbatical at the Max Planck Institute for Biogeochemistry in Jena, Germany. Additional funding was provided through the National Science Foundation 4W3336, EPSCoR 0553722 and KAN0061396/KAN006263. We would like to acknowledge data collection efforts by Tyler Buck and Austin Quick.

Edited by: R. Niven

\section{References}

Baum, K., Ham, J., Brunsell, N., and Coyne, P.: Surface boundary layer of cattle feedlots: Implications for air emissions measurement, Agr. Forest Meteorol., 148, 1882-1893, doi:10.1016/j.agrformet.2008.06.017, 2008.

Brunsell, N. A.: Characterization of land-surface precipitation feedback regimes with remote sensing, Remote Sens. Environ., 100, 200-211, doi:10.1016/j.rse.2005.10.025, 2006.

Brutsaert, W.: On a derivable formula for long-wave radiation from clear skies, Water Resour. Res., 11, 742-744, 1975.

Campbell, G. S. and Norman, J. M.: An introduction to environmental biophysics, Springer, 286, 1998.

Chen, F. and Dudhia, J.: Coupling an advanced land surfacehydrology model with the Penn State-NCAR MM5 modeling system. Part I: Model implementation and sensitivity, Mon. Weather Rev., 129, 569-585, 2001a.

Chen, F. and Dudhia, J.: Coupling an advanced land surfacehydrology model with the Penn State-NCAR MM5 modeling system. Part II: Preliminary model validation, Mon. Weather Rev., 129, 587-604, 2001b.

Chen, F. and Zhang, Y.: On the coupling strength between the land surface and the atmosphere: From viewpoint of surface exchange coefficients, Geophys. Res. Lett., 36, 1-5, doi:10.1029/2009GL037980, 2009.

Ek, M. B., Mitchell, K. E., Lin, Y., Rogers, E., Grunmann, P., Koren, V., Gayno, G., and Tarpley, J. D.: Implementation of Noah land surface model advances in the National Centers for Environmental Prediction operational mesoscale Eta model, J. Geophys. Res., 108, 1-16, doi:10.1029/2002JD003296, 2003.

Foken, T. and Wichura, B.: Tools for quality assessment of surfacebased flux measurements, Agr. Forest Meteorol., 78, 83-105, 1996.

Hammerle, A., Haslwanter, A., Schmitt, M., Bahn, M., Tappeiner, U., Cernusca, A., and Wohlfahrt, G.: Eddy covariance measurements of carbon dioxide, latent and sensible energy fluxes above a meadow on a mountain slope, Bound.-Lay. Meteorol., 122, 397-416, doi:10.1007/s10546-006-9109-x, 2006.

Holdaway, R. J., Sparrow, A. D., and Coomes, D. A.: Trends in entropy production during ecosystem development in the Amazon Basin, Philos. T. Roy. Soc. Lond. B, 365, 1437-1447, doi:10.1098/rstb.2009.0298, 2010.

Jones, A. R. and Brunsell, N. A.: Energy balance partitioning and net radiation controls on soil moisture-precipitation feedbacks, Earth Interact., 13, 1-25, doi:10.1175/2009EI270.1, 2009.
Katul, G., Lai, C., Albertson, J., Vidakovic, B., Schäfer, K., Hsieh, C., and Oren, R.: Quantifying the complexity in mapping energy inputs and hydrologic state variables into land-surface fluxes, Geophys. Res. Lett., 28, 3305-3307, 2001.

Kleidon, A.: Optimized stomatal conductance of vegetated land surfaces and its effects on simulated productivity and climate, Geophys. Res. Lett., 31, 1-4, doi:10.1029/2004GL020769, 2004.

Kleidon, A.: Optimized stomatal conductance and the climate sensitivity to carbon dioxide, Geophys. Res. Lett., 34, 1-4, doi:10.1029/2007GL030342, 2007.

Kleidon, A. and Schymanski, S.: Thermodynamics and optimality of the water budget on land: A review, Geophys. Res. Lett., 35, 1-6, doi:10.1029/2008GL035393, 2008.

LeMone, M. A., Chen, F., Alfieri, J. G., Tewari, M., Geerts, B., Miao, Q., Grossman, R. L., and Coulter, R. L.: Influence of land cover and soil moisture on the horizontal distribution of sensible and latent heat fluxes in southeast Kansas during IHOP_2002 and CASES-97, J. Hydrometeorol., 8, 68-87, doi:10.1175/JHM554.1, 2007.

LeMone, M. A., Tewari, M., Chen, F., Alfieri, J. G., and Niyogi, D.: Evaluation of the Noah land surface model using data from a fairweather IHOP2002 day with heterogeneous surface fluxes, Mon. Weather Rev., 136, 4915-4941, doi:10.1175/2008MWR2354.1, 2008.

Meyers, T. and Hollinger, S. E.: An assessment of storage terms in the surface energy balance of maize and soybean, Agr. Forest Meteorol., 125, 105-115, doi:10.1016/j.agrformet.2004.03.001, 2004.

Ozawa, H. and Ohmura, A.: Thermodynamics of a global-mean state of the atmosphere - a state of maximum entropy increase, J. Climate, 10, 441-445, 2010.

Patzek, T.: Thermodynamics of agricultural sustainability: The case of US maize agriculture, Crit. Rev. Plant Sci., 27, 272-293, doi:10.1080/07352680802247971, 2008.

Pauluis, O. and Held, I. M.: Entropy budget of an atmosphere in radiative convective equilibrium, Part I: Maximum work and frictional dissipation, J. Atmos. Sci., 59, 125-139, doi:10.1175/1520-0469(2002)059;0125:EBOAAI ${ }_{i} 2.0 . C O ; 2$, 2002a.

Pauluis, O. and Held, I. M.: Entropy budget of an atmosphere in radiative convective equilibrium, Part II: Latent heat transport and moist processes, J. Atmos. Sci., 59, 140-149, doi:10.1175/15200469(2002)059;0140:EBOAAI $i 2.0 . C O ; 2,2002 b$.

Paw U, K. T. P., Baldocchi, D. D., Meyers, T. P., and Wilson, K. B.: Correction of eddy-covariance measurements incorporating both advective effects and density fluxes, Bound.-Lay. Meteorol., 97, 487-511, 2000.

Peixoto, J. P., Oort, A. H., De Almeida, M., and Tomé, A.: Entropy budget of the atmosphere, J. Geophys. Res., 96, 10981-10988, 1991.

Prigogine, I., Nicolis, G., and Babloyantz, A.: Thermodynamics of evolution, Phys. Today, 25, 23-28, doi:10.1063/1.3071090, 1972.

R Development Core Team: R: A Language and Environment for Statistical Computing, R Foundation for Statistical Computing, Vienna, Austria, 2010. 
Schneider, E. D. and Kay, J. J.: Life as a manifestation of the second law of thermodynamics, Math. Comput. Modell., 19, 25-48, 1994.

Schroedinger, E.: What is life?, Cambridge University Press, 1945.

Sridhar, V.: Validation of the NOAH-OSU land surface model using surface flux measurements in Oklahoma, J. Geophys. Res., 107, 4418, doi:10.1029/2001JD001306, 2002.

Steinborn, W. and Svirezhev, Y.: Entropy as an indicator of sustainability in agro-ecosystems: North Germany case study, Ecol. Model., 133, 247-257, doi:10.1016/S0304-3800(00)00323-9, 2000.

Stephens, G. L. and O'Brien, D. M.: Entropy and climate. I: ERBE observations of the entropy production of the earth, Q. J. Roy. Meteorol. Soc., 119, 121-152, doi:10.1002/qj.49711950906, 1993.

Stewart, J., Kustas, W., Humes, K., Nichols, W., Moran, M., and de Bruin, H.: Sensible heat flux-radiometric surface temperature relationship for eight semiarid areas, J. Appl. Meteorol., 33, 1110-1117, 1994.

Svirezhev, Y.: Thermodynamics and ecology, Ecol. Model., 132, 11-22, doi:10.1016/S0304-3800(00)00301-X, 2000.
Tesar, M., Šír, M., Lichner, L., and Čermák, J.: Plant transpiration and net entropy exchange on the Earth's surface in a Czech watershed, Biologia, 62, 547-551, doi:10.2478/s11756-007-01082, 2007.

Wang, J., Bras, R. L., Lerdau, M., and Salvucci, G. D.: A maximum hypothesis of transpiration, J. Geophys. Res., 112, 1-11, doi:10.1029/2006JG000255, 2007.

Webb, E., Pearman, G., and Leuning, R.: Correction of flux for density effects due to heat and water vapour transfer, Q. J. Roy. Meteorol. Soc., 106, 85-100, 1980.

Wilson, K., Goldstein, A. P., Falge, E., Aubinet, M., Baldocchi, D., Berbigier, P., Bernhofer, C., Ceulemans, R., Dolman, H., Field, C., Grelle, A., Ibrom, A., Law, B. E., Kowalski, A., Meyers, T., Moncrieff, J., Monson, R. P., Oechel, W., Tenhunen, R. P., Valentini, R., and Verma, S. P.: Energy balance closure at FLUXNET sites, Agr. Forest Meteorol., 113, 223-243, 2002.

$\mathrm{Wu}, \mathrm{W}$. and Liu, Y.: Radiation entropy flux and entropy production of the Earth system, Rev. Geophys., 48, 1-27, doi:10.1029/2008RG000275, 2010. 